\title{
PART I I Vegetable
}

Although wood must have been extensively used for handles, shafts, bows and other purposes, disappointingly little was found in the way of finished objects, owing no doubt in part to the soft condition in which it survived.'

(Clark 1954, 178)

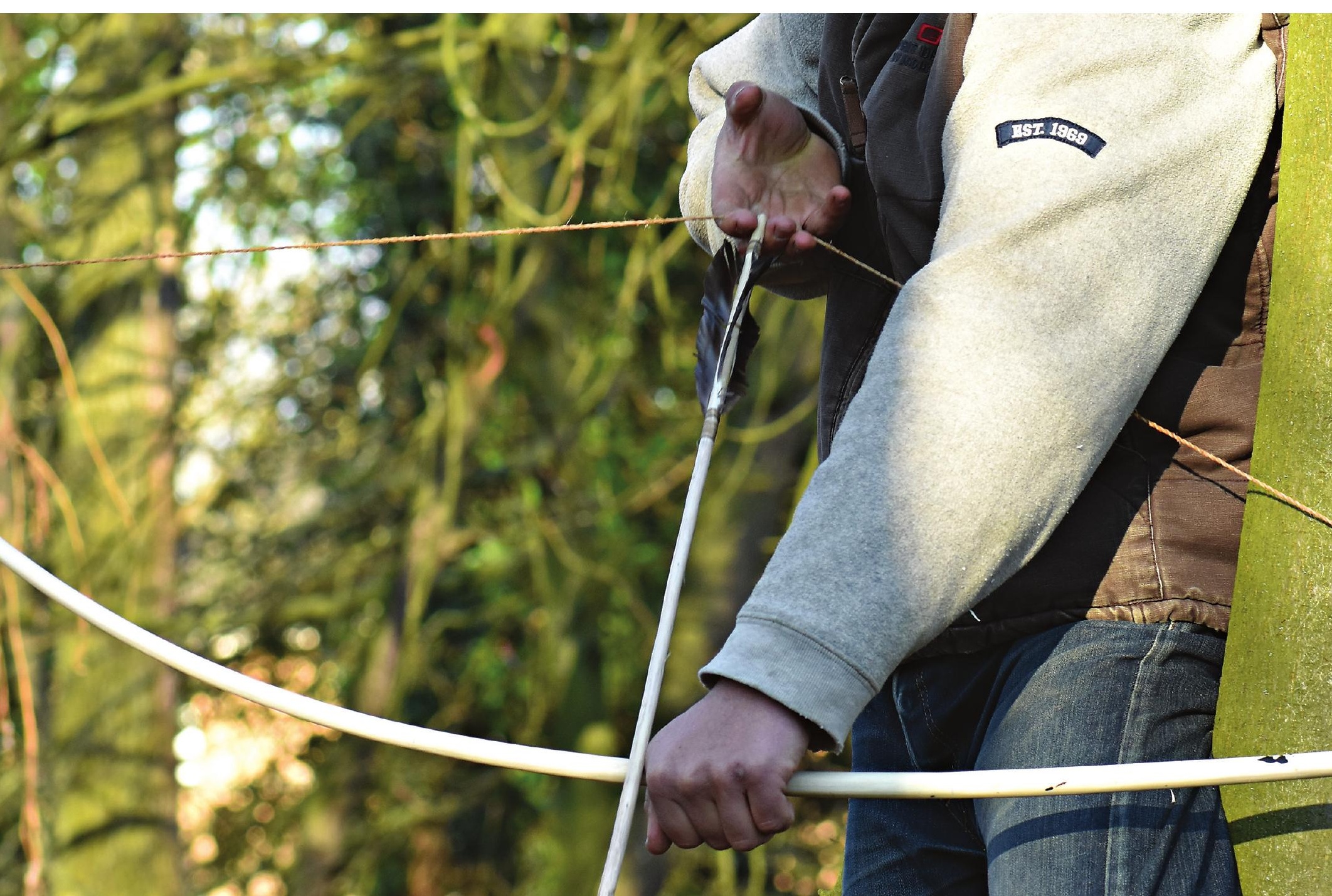





\title{
Woodworking Technology
}

\author{
Michael Bamforth, Maisie Taylor, Diederik Pomstra, Aimée Little and \\ Anita Radini
}

\section{Introduction}

There are 1602 pieces of worked wood recorded from Star Carr that have been split, trimmed or hewn and this forms both the earliest and largest Mesolithic woodworking assemblage in the UK. The assemblage is varied and contains finished artefacts, large split and unsplit timbers, entire trees and roundwood stems, rods and poles. However, woodworking is a reductive technology and there is also a significant quantity of woodworking debris of various sizes from large off-cuts (timber debris) to small woodchips, detached by a single blow of an axe. Traces recorded from the wood assemblage provide evidence for the Mesolithic woodworking tool kit and the material itself provides a glimpse of the types of woodland that were being exploited, and possibly even managed. Overall, the wood assemblage and the evidence of woodworking it contains is relatively uniform across the site and across the centuries of occupation and appears to represent a single, distinct, woodworking tradition.

This chapter sets out how the raw material itself may have been selected and the potential relationship between people and the landscape around them. It examines the possible evidence for coppicing as well as the evidence for beaver-gnawed wood, before examining in detail the tools, technology and skills required to work the wood. This chapter should be read in conjunction with the research on wooden structures (Chapter 6), wooden artefacts (Chapter 29) and the use of bark (Chapter 30).

\section{Evidence for beaver activity}

European beavers (Castor fiber) are present in the faunal assemblage at Star Carr, with some evidence that the mandibles may have been utilised as tools (Chapter 23). There is also evidence for their activity within the wood assemblage, in terms of distinct and unique gnawing marks. These gnaw marks have been identified on the basis of modern reference material, published literature (Coles 2006) and the authors' previous experience (MT and $\mathrm{MB}$ ).

Figure 28 (page 345): Diederik Pomstra shooting a replica bow and arrow (Copyright Aimée Little, CC BY-NC 4.0).

How to cite this book chapter:

Bamforth, M., Taylor, M., Pomstra, D., Little, A. and Radini, A. 2018. Woodworking Technology. In: Milner, N., Conneller, C. and Taylor, B. (eds.) Star Carr Volume 2: Studies in Technology, Subsistence and Environment, pp. 347-366. York: White Rose University Press. DOI: https://doi.org/10.22599/book2.n. Licence: CC BY-NC 4.0 
The beaver is a large rodent (c. $20-25 \mathrm{~kg}$ ) that generally lives near water including rivers, streams and lakes (Coles 2006). The lake edge setting at Star Carr combined with the wooded landscape would have provided an ideal habitat. Beavers will generally build a burrow dug into banks at the edge of the water, with ingress from a sub-aqua entrance. In environments where it is not possible to dig a burrow, beavers will construct a lodge from a heap of wood and gnaw out a burrow within it (Coles 2006). Beavers are vegetarians with a broad diet that can include leaves, twigs and bark. In the search for food or material for a lodge, beavers are capable of felling saplings and even substantial trees (Coles 2006).

Following the identification of beaver-gnawed wood from the brushwood 'platform' Coles $(2006,78)$ suggested that the accumulation of wood recorded by Clark may have been partially, or wholly, the result of beaver activity. However, although there is some beaver-modified material present within this area, only two items displaying these traces were recovered from Clark's area during the recent excavations, suggesting the role of beavers in the accumulation of this material is minimal at best (see Chapter 6).

Overall, 24 items show evidence of beaver modification: 22 pieces of roundwood, one piece of roundwood debris and a timber classed as a tree (a side branch has been beaver gnawed). These were recovered from the brushwood $(n=6)$, detrital wood scatter $(n=11)$, central platform $(n=1)$, Clark's area $(n=2)$ and the western platform $(n=4)$. The majority of the material has been gnawed through at one or both ends or a small side branch. A single item showed the classic 'melon slice' that can be caused by a beaver gnawing through one face (Figure 28.1). These types of modification, i.e. gnawing along the shaft to consume bark for food and gnawing of ends to acquire building material or for food, are all within the range of normal beaver behaviour.

Although much of this material was recovered towards the base of the sequence, often below culturally modified material, some of the items have also been anthropogenically modified. Of key interest to this study are three items which show possible evidence of both human and beaver modification: $\langle 116509\rangle$ is half split roundwood debris that may represent cultural or natural modification and that has also been beaver gnawed at one end; <109099> appears to have been trimmed with an axe or adze and beaver gnawed at the same end; $<103190>$ has been beaver gnawed at the proximal end and one side branch whilst the distal end has been trimmed with an axe or adze and torn in a chop and tear (see below). Coles (2010) has suggested that during later prehistory, people may have been drawn to beaver-modified landscapes, either to hunt the beavers or to take advantage of areas cleared of tree cover by the animals, an assertion that may have some relevance at Star Carr.

\section{Raw material}

Selecting the right tree is essential to successful woodworking. Choosing a tree with the required characteristics, be it straightness or curve of the grain, the presence/absence of side branches and knots, or size and form is the first step to successfully manufacturing the wooden objects required. The people living at Star Carr would have had a close relationship with their surrounding landscape, spending time hunting large and small prey and gathering food and other materials from the surrounding woodland. These forays into the woodland would have drawn their attention to a wide range of woodland resources. Warren $(2003,22)$ reminds us that Mesolithic gatherer-hunter communities would have had personal relationships with the woodlands they lived alongside and within, and that the woodlands themselves were not the pristine, wild spaces sometimes invoked

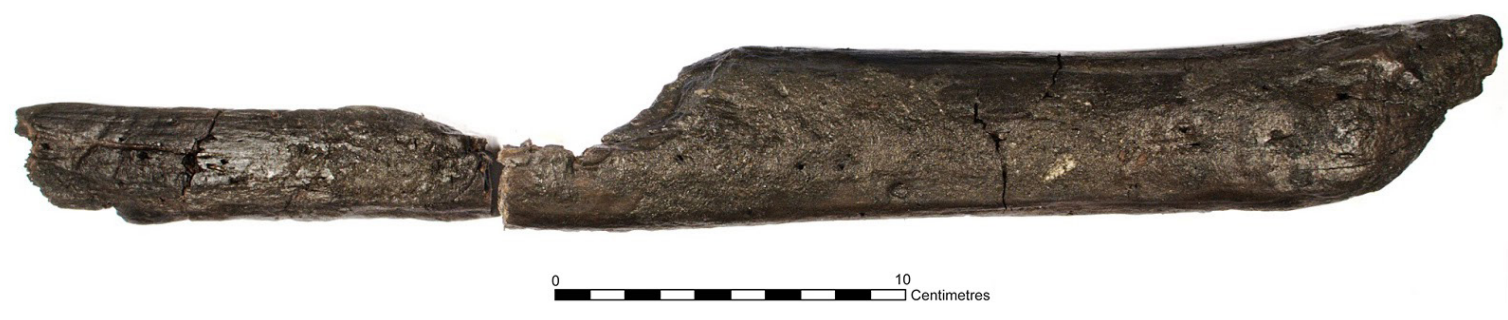

Figure 28.1: Roundwood $<99927>$. Both ends are beaver gnawed and there is a distinct 'melon slice' beaver gnaw along the stem (Copyright Michael Bamforth, CC BY-NC 4.0). 
in archaeological narrative, but living spaces criss-crossed by paths and route ways (produced by humans and animals) and with locations imbued with memories and meaning.

From the material evidence for specific woodworking practices at Star Carr it is clear that people were knowledgeable and selective regarding the type and quality of wood they utilised, and by extension, aware of the location of suitable trees in the surrounding landscape. As Taylor (2010) points out, trees are the largest living things encountered by the majority of human beings. They exist on a timescale that is often longer than that of a human and as a result might have appeared 'other worldly'. Wood can be harvested without killing the tree, as is the case with coppiced or pollarded rods and perhaps, as discussed below, planks cleft from the outer surface of a standing tree. Alternatively, a tree can be felled, making all of its wood available, though bringing the life of the tree to an end.

The majority of the larger-diameter pieces of wood encountered at Star Carr are derived from the trunks of trees as opposed to the limbs, as inferred from the centrally located piths. This is based on the propensity for hardwood trees (dicotyledons) to support branch wood in tension, leading to an eccentrically located pith (Jane 1970, figure 108). As such, the larger diameters are describing the trunk sizes of trees felled from the surrounding landscape. The largest piece on site has a diameter of $350 \mathrm{~mm}$; however, a large proportion is below $180 \mathrm{~mm}$ (Figure 28.2). The pieces with the largest diameters are generally complete trees which have either been utilised within the lake edge timber platforms or have been growing at the lake edge and have fallen into the upper lacustrine deposits. The longest is a tree which is $10.3 \mathrm{~m}$ long (Figure 28.2). The trees that have been used for the wooden platforms have straighter grains and fewer side branches, suggesting that these have been growing in denser woodland cover than those growing along the edge of the lake (Figure 28.3 and Figure 28.4).

A significant part of the assemblage is formed of rods, poles and other small diameter roundwood. The larger items are likely to be the trunks of smaller trees and saplings whilst some of the smaller material has morphological traits suggestive of coppicing (Figure 28.3 and 28.4). Whether derived from coppiced woodland or not, the presence of so many straight-stemmed roundwood rods and poles points to strong selection criteria for this trait.

There is widely accepted evidence from historic periods in the UK for extensive woodland management in the form of large standards interspersed with understorey coppice. The resulting rods were utilised for basketry, construction (wattle) and charcoal production. During later periods, coppicing was often carried out on a rotation cycle of several years (Rackham 2006). Evidence for possible managed coppice from Britain and Ireland dates back to the Late Mesolithic in the Liffey estuary, Dublin, Ireland (McQuade and O'Donnell 2007).

The problems inherent in attempting to identify possible woodland management or forestry in assemblages of roundwood stems has been discussed in detail elsewhere (Out et al. 2013; Warren et al. 2014). Warren (2014) rehearses a series of debates around the nature of any possible resource management in terms of both purposive versus opportunistic resource exploitation (Brown 1997) or the visibility of less-defined practices such as adventitious coppice (Crone 1987) or draw felling (selecting stems for the required diameter) (Rackham 2006). Caution in inferring management practices is advised.

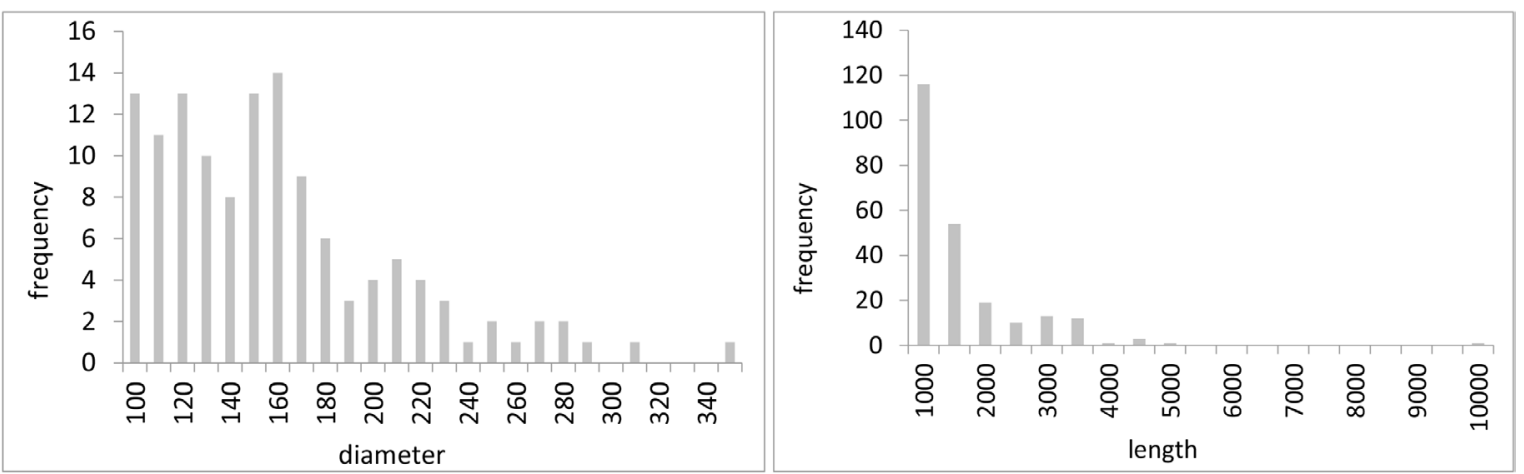

Figure 28.2: (left) frequency of diameters and reconstructed diameters over $100 \mathrm{~mm}(\mathrm{n}=127)$. Reconstructed diameters have been inferred where a complete radius from pith to bark edge is present; (right) lengths greater than $1000 \mathrm{~mm}(\mathrm{n}=250)$ (Copyright Star Carr Project, CC BY-NC 4.0). 

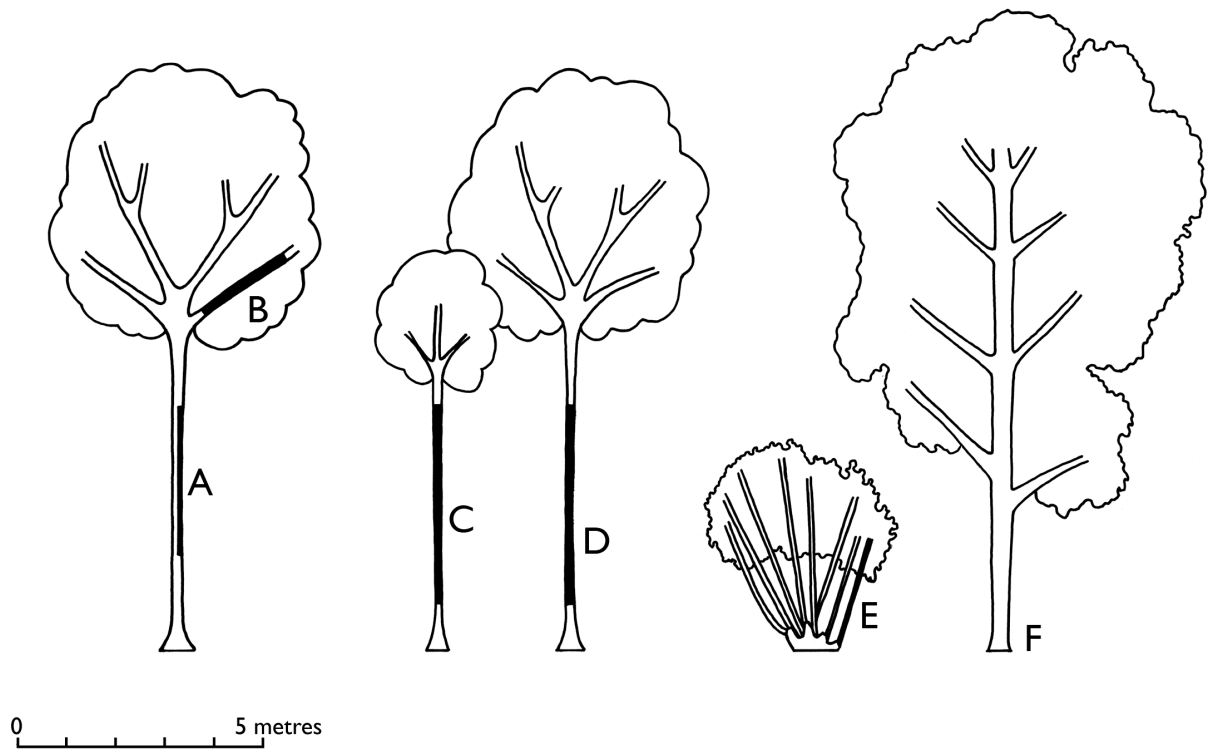

Figure 28.3: Woodscape Model: a) tangential outer split from knot free trunk; b) tree limbs; c) trunks of young trees; d) entire straight-grained tree trunks; e) 'coppiced' rods; f) lake edge trees with frequent low side branches (Copyright Chloe Watson, CC BY-NC 4.0).

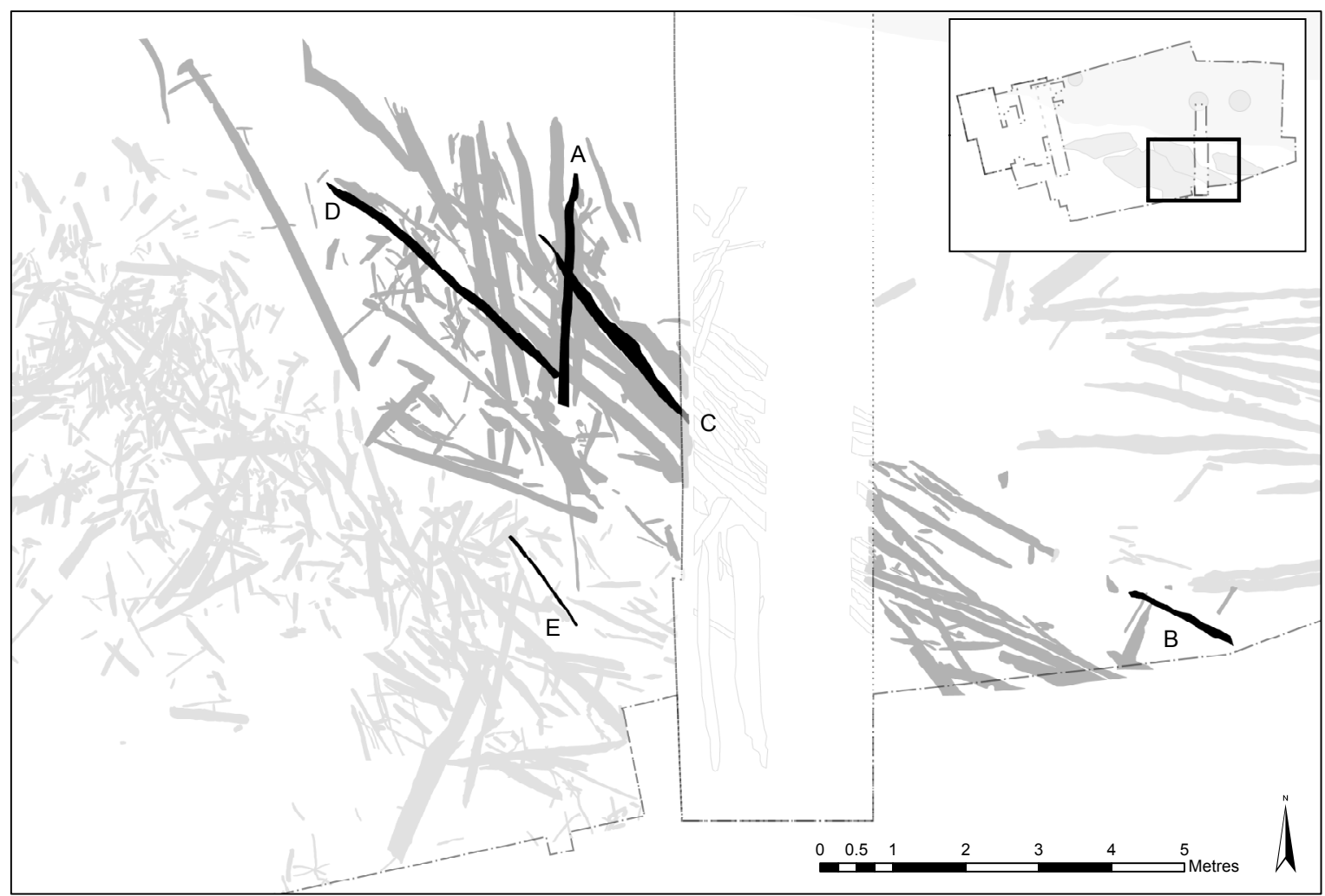

Figure 28.4: Elements used to construct woodscape model seen within the central platform (see Figure 28.3) (Copyright Star Carr Project, CC BY-NC 4.0). 
Throughout this volume, reference is made to pieces of roundwood that appear to be coppiced. There is no assertion that these are the result of planned or deliberate coppicing or pollarding, although this is a possibility. There is clear evidence of both beaver and human populations felling trees, and many of these would have regenerated, producing coppice stems or rods. Whether coppicing was carried out as a deliberate act or the stems resulted from felling, such stems would almost certainly have been available within the local landscape and people presumably would have harvested them for use. The presence of a large number of long straight stems and poles recovered from the site shows a strong selection criteria for the harvesting of this type of material, which would have been useful for building structures, such as those seen on the dryland (Chapter 5), or perhaps for weaving wattle.

In the analysis of the wood from Star Carr, roundwood was noted as having possible morphological evidence for coppicing when a straight stem with a relatively uniform diameter and a central pith was present (Figure 28.5). Additional morphological characteristics that may be indicative of coppicing as identified by Rackham (1977) were also noted, such as a curved and/or flared butt/proximal end, or stems with evidence of topping. In terms of the prevalence of possibly coppiced roundwood across the different spatial analytical areas, there is a tendency for the two scatters of wood (detrital wood scatter and Clark's area) to have a higher incidence than the three lake edge platforms (Table 28.1).

Growth ring count studies are often carried out on archaeological assemblages of roundwood that appear to be the result of coppicing, with the intent of identifying rotational cycles. However, coppicing can also be carried out on an ad hoc basis and even if a rotational cycle is in place, practices such as draw felling can negate the evidence of any possible rotational cycle. Although recent research (Out et al. 2013) highlights the potential difficulties of identifying deliberate coppicing through growth ring count analysis, it seems pertinent to consider this data.

Growth ring count and seasonality of felling analysis was attempted from the Star Carr assemblage for items identified as having morphological traits associated with coppicing and a control group that did not. Unfortunately, the relatively poor condition of the material at a cellular level, combined with the high rates of

\begin{tabular}{|l|r|}
\hline Area & $\begin{array}{l}\text { Roundwood with } \\
\text { morphological } \\
\text { evidence suggestive } \\
\text { of coppicing }\end{array}$ \\
\hline Brushwood & $1 \%$ \\
\hline Detrital wood scatter & $17 \%$ \\
\hline Central platform & $8 \%$ \\
\hline Eastern platform & $0 \%$ \\
\hline Western platform & $10 \%$ \\
\hline Clark's area & $44 \%$ \\
\hline
\end{tabular}

Table 28.1: Percentage of roundwood assemblage by area, which displays morphological traits associated with coppicing.

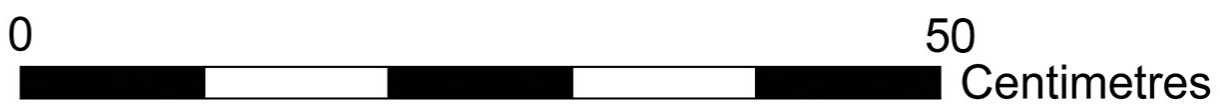

Figure 28.5: Long, straight stem <103437> (Copyright Michael Bamforth, CC BY-NC 4.0). 
compression, severely hampered data collection and it was not possible to acquire a large enough dataset to be statistically viable for meaningful analysis. However, the data that were acquired are considered below.

A total of 78 growth ring counts were recorded ( 76 of these were from roundwood and two from roundwood debris with a complete radius from pith to bark edge present), 48 of which showed morphological evidence for possible coppicing (Table 28.2). The growth ring counts derived from all the spatial analytical groups and across species are considered together (Tables 28.2 and 28.3) (for further information regarding species identification, see Chapter 15).

It is often possible to record the season in which an item has been felled, via microscopic examination, from the presence of early or late wood at the bark edge (Jane 1970: 68). However, due to the poor condition of the wood, this deduction was only possible for ten items, all of which have approximately two growth rings, the results of which provide no discernible patterning regarding seasonality of felling/harvesting (Table 28.4).

Due to the poor condition, many of the ring counts were given as an estimated range which for the purposes of this study have been assigned a median value (e.g. $3-4$ years $=3.5$ years). Out et al. (2013) have shown that stems in the 20-60 mm range will often have an older age for a given diameter when derived from unmanaged as opposed to managed woodland resources. The age distribution for managed assemblages has also been shown to generally have a sharper cut-off in comparison to unmanaged stems (Out et al. 2013). When plotting growth ring count against diameter, no clustering is noted for either roundwood with or without morphological evidence suggestive of coppicing (Figure 28.6). The roundwood with morphological evidence for possible coppicing does show this trend for slightly higher age for a given diameter but there is no sharp cut off of growth rings (Figure 28.6). However, there is a marked tendency for the stems showing possible morphological coppicing evidence to cluster strongly in the 2-3 years of growth range, despite no such clustering being noted amongst the horizontal diameters, a trait that may be suggestive of some form of woodland management (Figure 28.7).

\begin{tabular}{|l|r|r|r|r|r|r|}
\hline $\begin{array}{l}\text { Morphological evidence for } \\
\text { possible coppicing? }\end{array}$ & Brushwood & $\begin{array}{l}\text { Detrital } \\
\text { wood scatter }\end{array}$ & $\begin{array}{l}\text { Western } \\
\text { platform }\end{array}$ & $\begin{array}{l}\text { Central } \\
\text { platform }\end{array}$ & Other & Total \\
\hline Yes & 3 & 36 & 1 & 4 & 4 & 48 \\
\hline No & 1 & 27 & 1 & 0 & 1 & 30 \\
\hline Total & 4 & 63 & 2 & 4 & 5 & 78 \\
\hline
\end{tabular}

Table 28.2: Roundwood and roundwood debris growth ring counts assigned to area.

\begin{tabular}{|c|c|c|c|c|c|c|}
\hline $\begin{array}{l}\text { Morphological evidence for } \\
\text { possible coppicing? }\end{array}$ & willow & willow/aspen & aspen & birch & birch/alder/ hazel & Total \\
\hline Yes & 12 & 1 & 5 & 9 & 3 & 30 \\
\hline No & 39 & 0 & 6 & 3 & 0 & 48 \\
\hline Total & 51 & 1 & 11 & 12 & 3 & 78 \\
\hline
\end{tabular}

Table 28.3: Roundwood and roundwood debris growth ring counts assigned to taxa.

\begin{tabular}{|l|r|r|r|}
\hline Morphological evidence for possible coppicing? & c. 2 years growth, early wood & $\begin{array}{l}\text { c. 2 years growth, } \\
\text { late wood }\end{array}$ & Total \\
\hline Yes & 3 & 3 & 6 \\
\hline No & 2 & 2 & 4 \\
\hline Total & 5 & 5 & 10 \\
\hline
\end{tabular}

Table 28.4: Early and late felled/harvested material. 


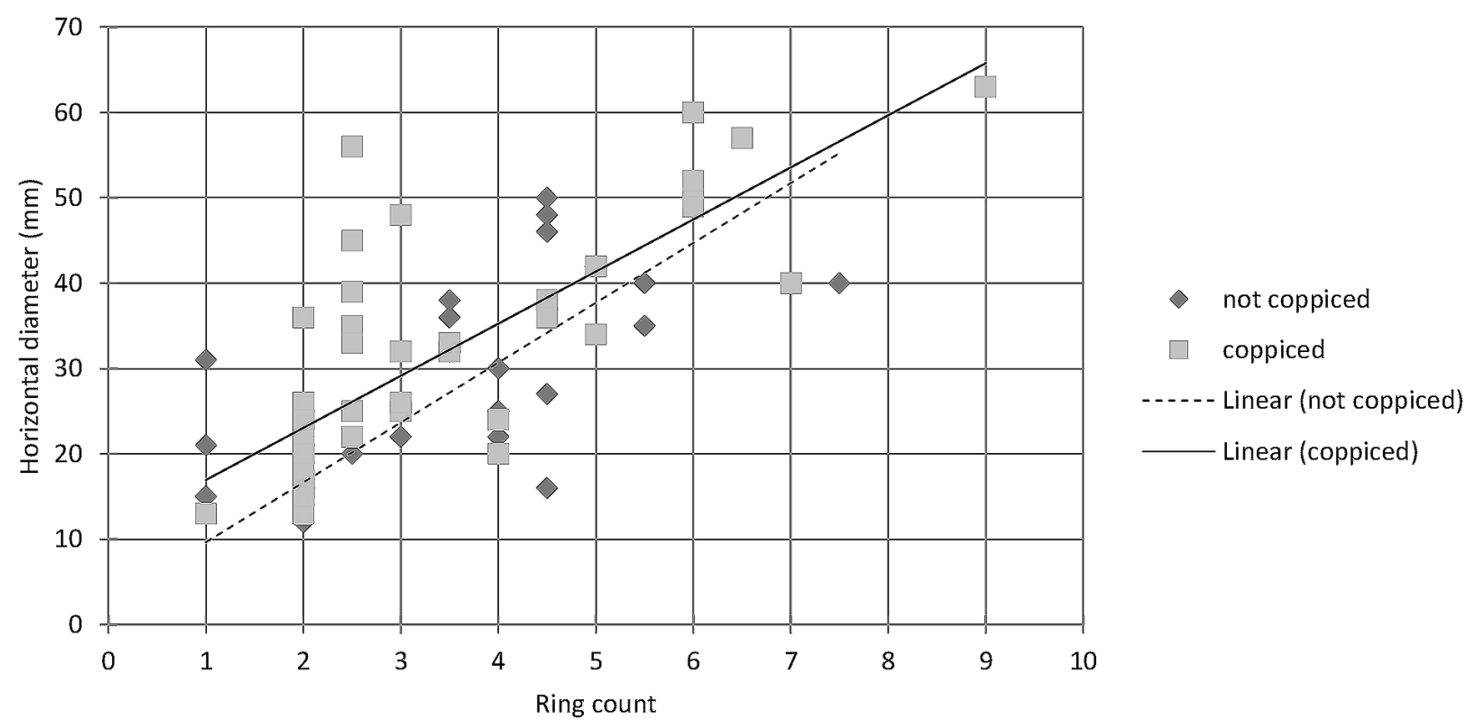

Figure 28.6: Growth ring count plotted against diameter for material with morphological traits indicative of coppicing and material without morphological traits indicative of coppicing (Copyright Star Carr Project, CC BY-NC 4.0).
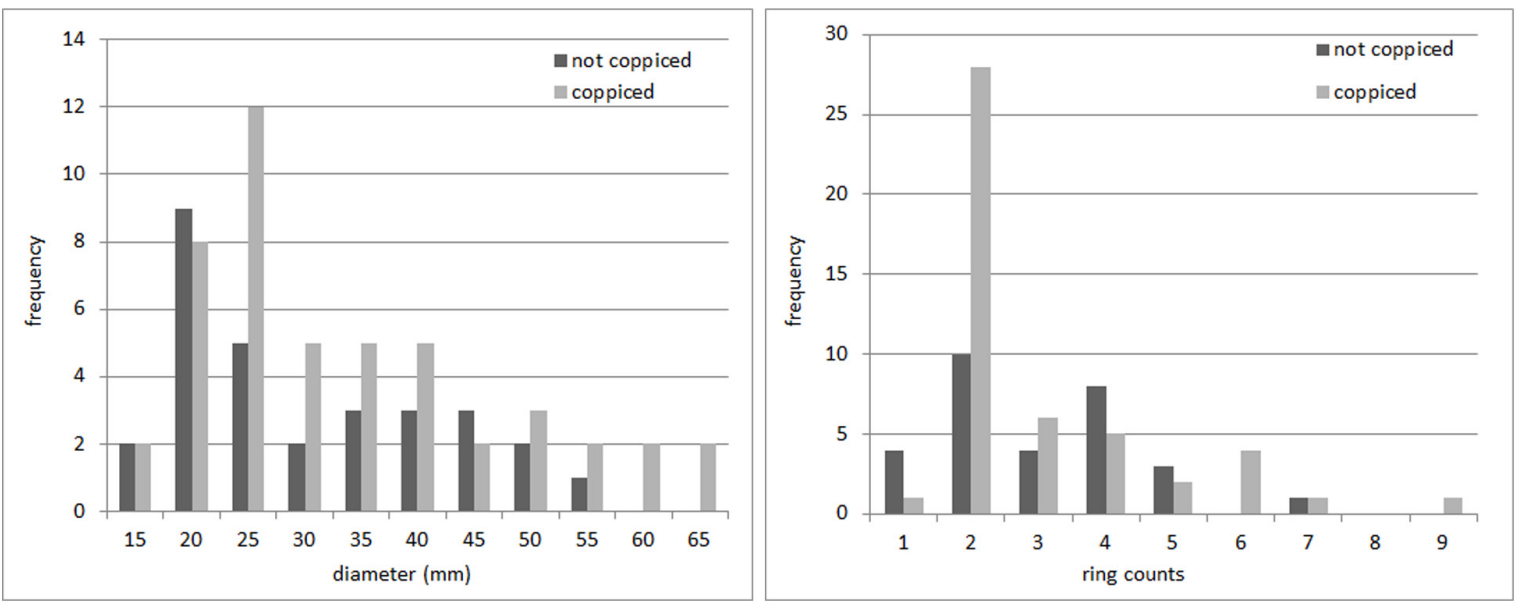

Figure 28.7: (left) frequency of horizontal diameters for material showing morphological signs of coppicing and material without morphological traits indicative of coppicing; (right) frequency of years of growth for material showing morphological signs of coppicing and material without morphological traits indicative of coppicing (Copyright Star Carr Project, CC BY-NC 4.0).

In sum, although no conclusive evidence for coppicing or pollarding has been found, there is certainly a strong selection bias for straight, even stems, rods and poles amongst the wood encountered at Star Carr, and deliberate woodland management strategies remain a strong possibility. 


\section{Technology}

The majority of prehistoric woodworking is based on two core principles:

1. Use of edged tools such as axes and adzes to fell trees and trim and hew timbers into shape by reducing the items down blow by blow, chip by chip.

2. Use of wedges and hammers to split or cleave logs longitudinally in the tangential and radial planes into the shapes required.

The woodworkers at Star Carr were prolific wood splitters, working in the tangential and radial planes and producing split timbers up to $3.6 \mathrm{~m}$ in length (Figure 28.8). Some of the split material is unusually long for any prehistoric woodworking assemblage (Bamforth 2010; Taylor 2001; Taylor 1998b) and shows a very high level of competence in this particular technique.

Tool facets provide us with evidence for hewing and trimming and many of the well-finished wooden artefacts illustrate the woodworker's depth of understanding of dowel technology. The presence of a two-stem twisted willow withy similarly displays an understanding of plying and cord production (Chapter 29).

It is reasonable to assume that the majority of the pieces of wood displaying traces of working at Star Carr will have been trimmed to length with an axe or adze. However, there is a low prevalence of tool facets or stop marks; it seems that the ends of the majority of the wood assemblage, where the longitudinal cellular structure of the wood is truncated and exposed, have degraded to such an extent that few tool facets remain. Where they are visible, the facets tend to be short, narrow and concave, as would be expected from the relatively obtuse cutting edge of stone tools (Coles and Orme 1978; Coles and Orme 1984; Sands 1997). A single stop mark was recorded from debris $<103726>$ and measured 40:4 mm (Figure 28.9).

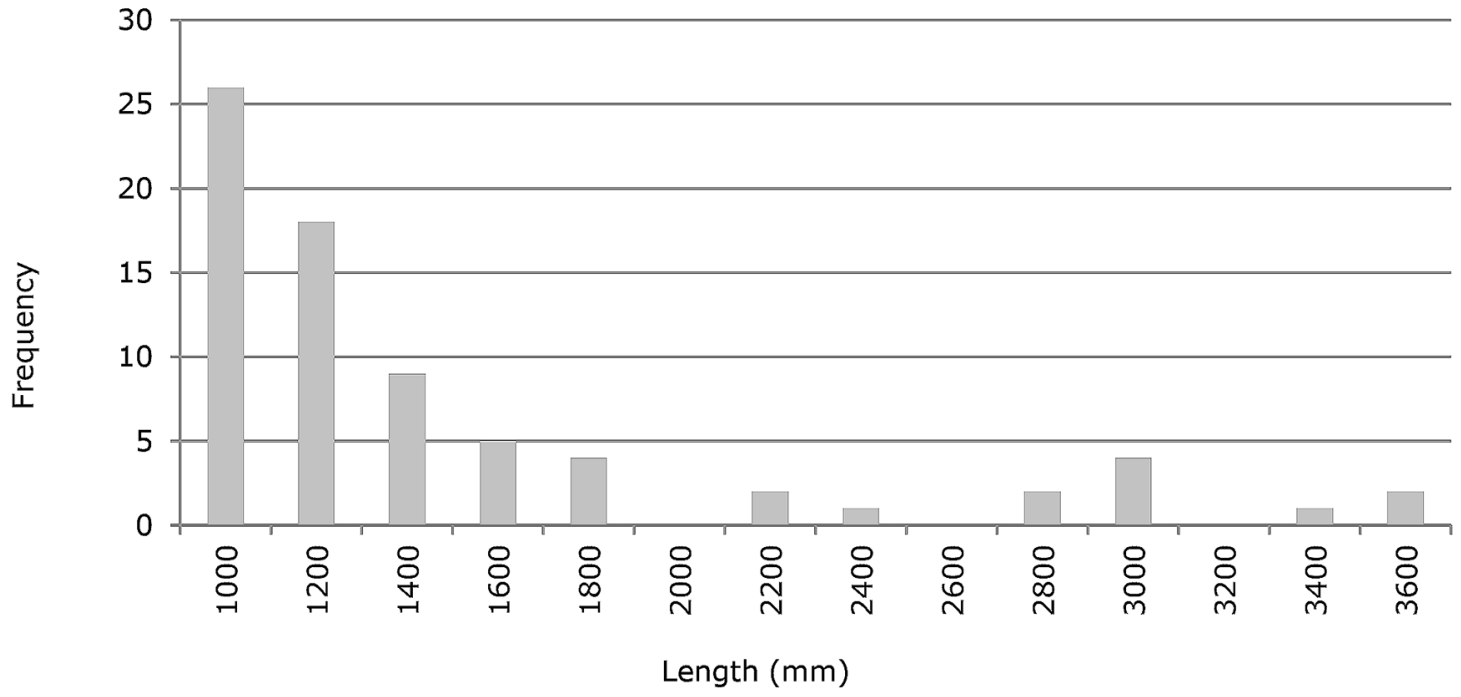

Figure 28.8: Lengths of split items greater than $1000 \mathrm{~mm}(\mathrm{n}=74)$ (Copyright Star Carr Project, CC BY-NC 4.0).

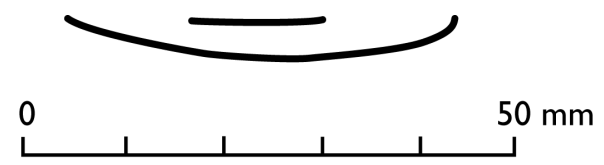

Figure 28.9: Tracing of stop mark left by the cutting edge of a flint axe or adze on the face of debris $<103726>$ (Copyright Chloe Watson, CC BY-NC 4.0). 
There are several woodworking features that stand out amongst the Star Carr assemblage as being unique or very unusual. These include the high prevalence of tangential outer splits, the high prevalence of parallel sided split items, the high prevalence of split timbers with the split fading/feathering out at one or both ends, the presence of longitudinal grooves on split faces, the presence of long, thin strips of woodworking debris and the presence of diagonal groove/gouge marks on split faces. The presence of these traces has led to the formulation of various hypotheses to explain the techniques that may have produced them, some of which have been tested through experimentation.

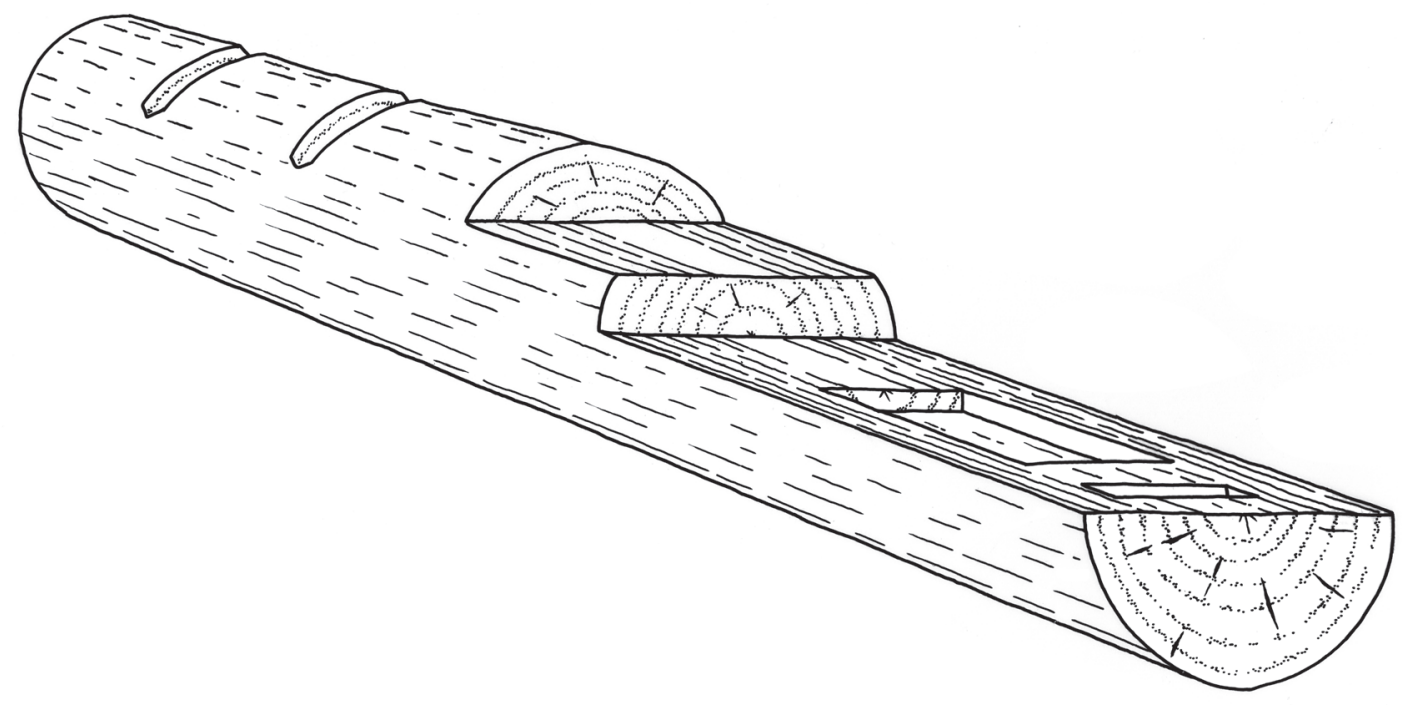

Figure 28.10: Notch-and-split technique (Copyright Chloe Watson, CC BY-NC 4.0).
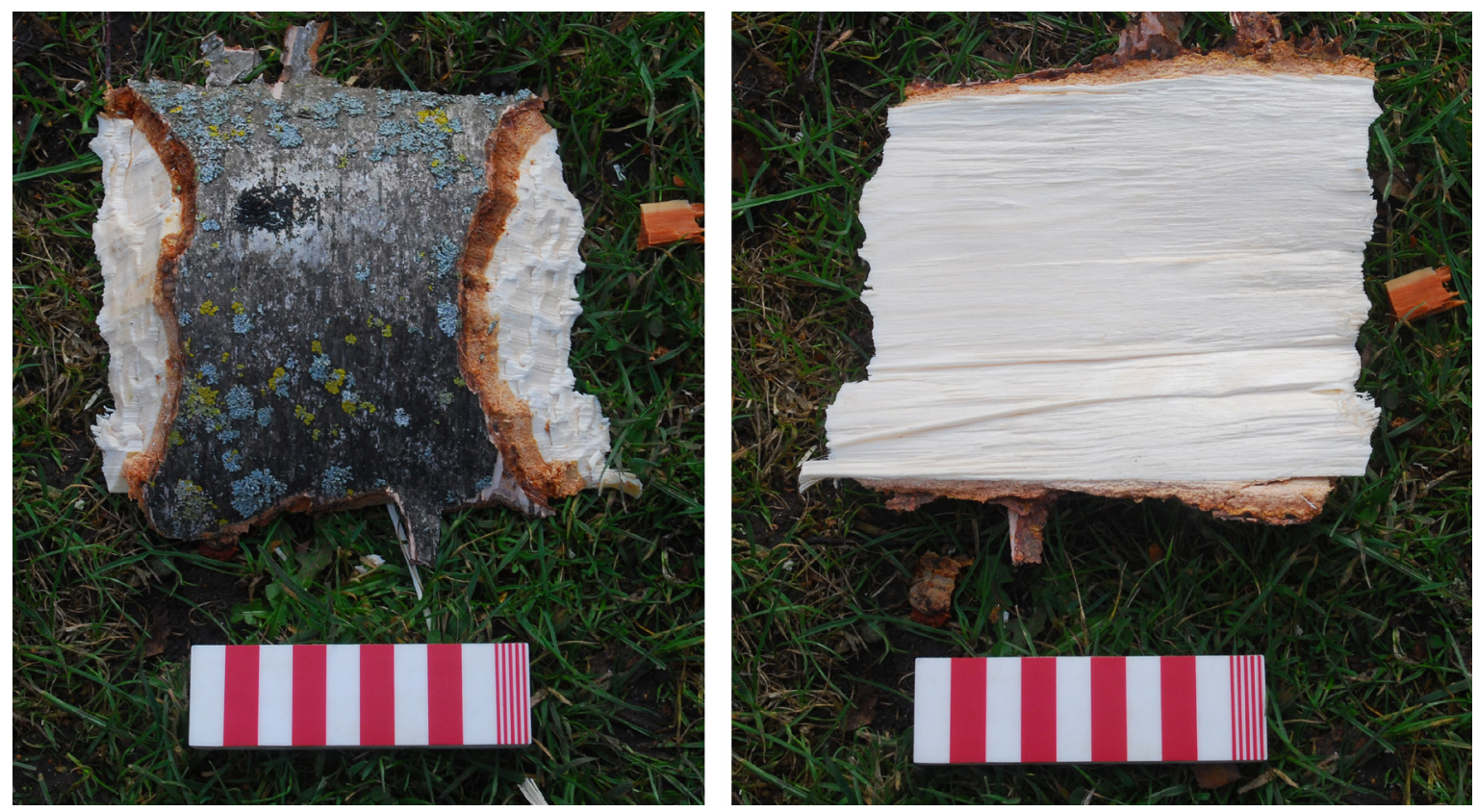

Figure 28.11: Notch-and-split debris produced during experimental work (Copyright Michael Bamforth, CC BY-NC 4.0). 
Notch-and-split woodworking techniques can be used for felling trees (Jørgenson 1985; Stewart 1984, 38), facing up logs (Stewart 1984, 42) and hollowing out log boats (Stewart 1984, 54; Christensen 1999, figure 9.2). The authors are aware of this technique and the distinct 'blocks' of debris it produces (Figures 28.10 and 28.11). Three pieces of debris that may have been produced by this technique were identified during the excavation:

- $\quad<99215>, 205 \times 82 \times 7 \mathrm{~mm}$, tangentially split.

- $<103715>, 160 \times 74 \times 10 \mathrm{~mm}$, tangential outer split.

- $<103805>, 418 \times 115 \times 65 \mathrm{~mm}$, tangential outer split, torn down both sides; appears to be from base of small tree.

As has been discussed elsewhere in the volume (Chapter 29) there is no extant evidence for the use of fire either to shape wood through charring and scraping or to harden wood. In addition, with the exception of a small hole drilled through wooden artefact $<115952>$, probably with a flint awl, there is no evidence from Star Carr for any other joints or fixings of any type. There is also no evidence for boat building though it is likely that people at Star Carr had watercraft of some kind to navigate the lake and visit the islands, and a possible paddle was found by Clark (see Chapter 29 for full discussion). Although unlikely, there are three pieces of debris that may be derived from notch-and-split woodworking (Stewart 1984, 54; Christensen 1999, Fig. 9.2) that could conceivably be the by-product of log boat building.

The low prevalence of vertical elements in the forms of stakes, posts or piles is very unusual and worthy of note. This is limited to five stakes: three roundwood and two utilised pieces of debris (Chapter 29) and to the indirect evidence provided by the stakeholes and postholes of the dryland structures (Chapter 5).

\section{Tools}

The wood assemblage provides us with indirect evidence of the tools used in the form of the traces they have left on the wood. At Star Carr, a strong case can be made for woodworking activities being undertaken with bone, antler and flint tools. Microwear traces of woodworking on flint has been identified on a number of flint tools, initially by Dumont $(1983,1988)$, and more recently, as part of this project (Chapter 35). Although it was not possible to identify wood traces on osseous tools due to the poor condition and, in the case of the bone chisel, a re-sharpening event, experimental research demonstrated the high likelihood of their employment in woodworking tasks. Wood hafting traces on flint tools provides further indirect evidence of the diversity of uses wood as a raw material had at Star Carr

Flint tranchet axes are well represented in the flint assemblage and may have been hafted as either axes or adzes, most probably in a haft constructed from a willow heartwood dowel (Figure 28.12). Microwear traces of wood polish suggestive of these tools being used for trimming and chopping wood have been recovered from tranchet flake $<98825>$ (refit group 89 , Chapter 8), axe $<92077>$, recovered from the eastern structure and two further small axes (<99469> and $<94367>$, refit group 88, Chapter 8). Dumont (1983) also identified a core resharpening flake with woodworking traces.

Woodworking microwear traces have been recovered from several other flints. A Type E disc core (part of scatter AC8, Dumont 1983) is identified as a woodworking tool. Five burins with microwear traces of wood polish show evidence of scraping, grooving and whittling. Five blades show microwear traces resulting from use as woodworking tools: two utilised as borers and three as scrapers. Just one scraper displays woodworking traces, though it is possible that re-sharpening events removed evidence of use on wood and other contact materials from these tools. Notched/denticulate tools with transverse woodworking traces within the retouched zone indicate the use of these tools to scrape and/or burnish wood, possibly shafts. The circular, waisted, hourglass-shaped hole worked through wooden artefact $\langle 115952\rangle$ provides indirect evidence for the possible use of flint awls on wood (Chapter 29). This is further supported by Dumont's (1983) microwear work

Figure 28.12 (page 357): Flint tranchet adze in use to prepare a tree trunk for splitting a tangential outer timber from a standing tree (Copyright Don Henson, CC BY-NC 4.0). 


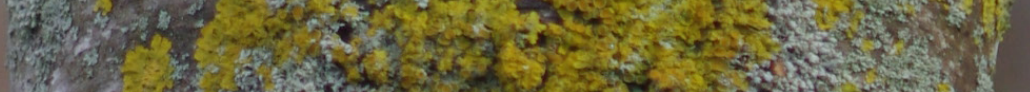

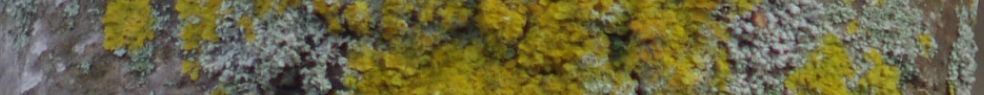

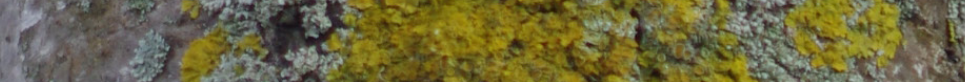

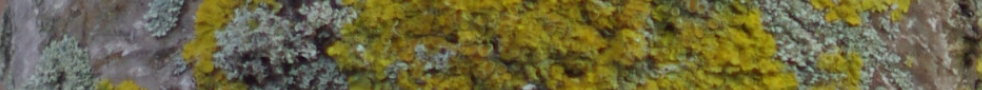

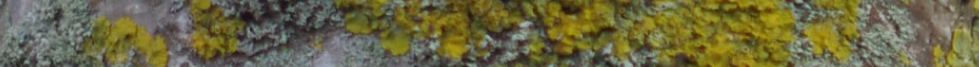

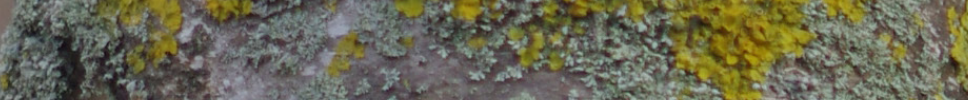

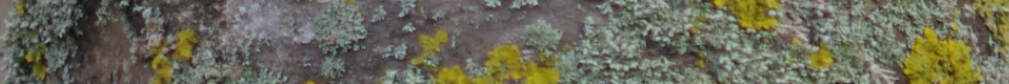

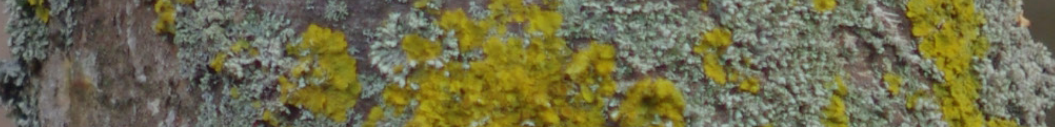

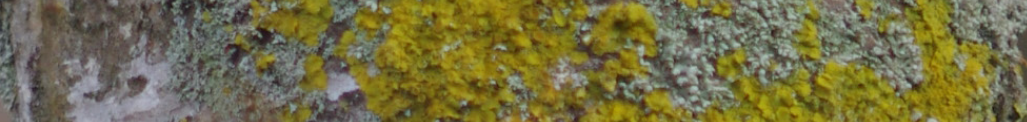

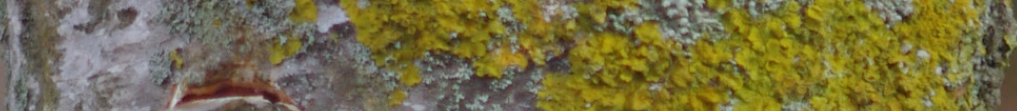

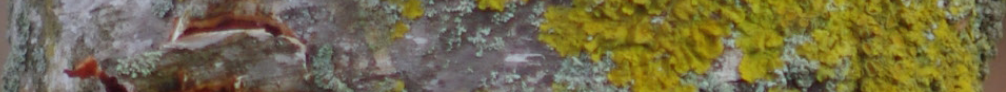

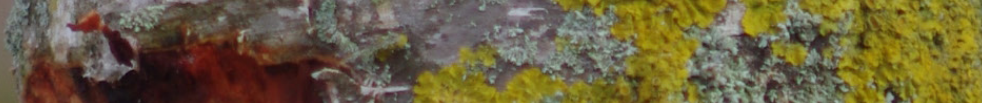

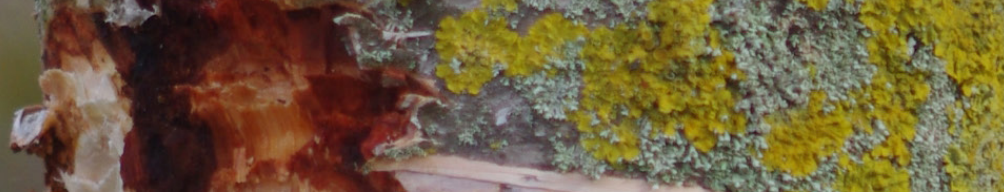

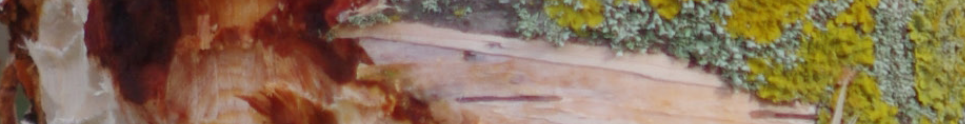

13

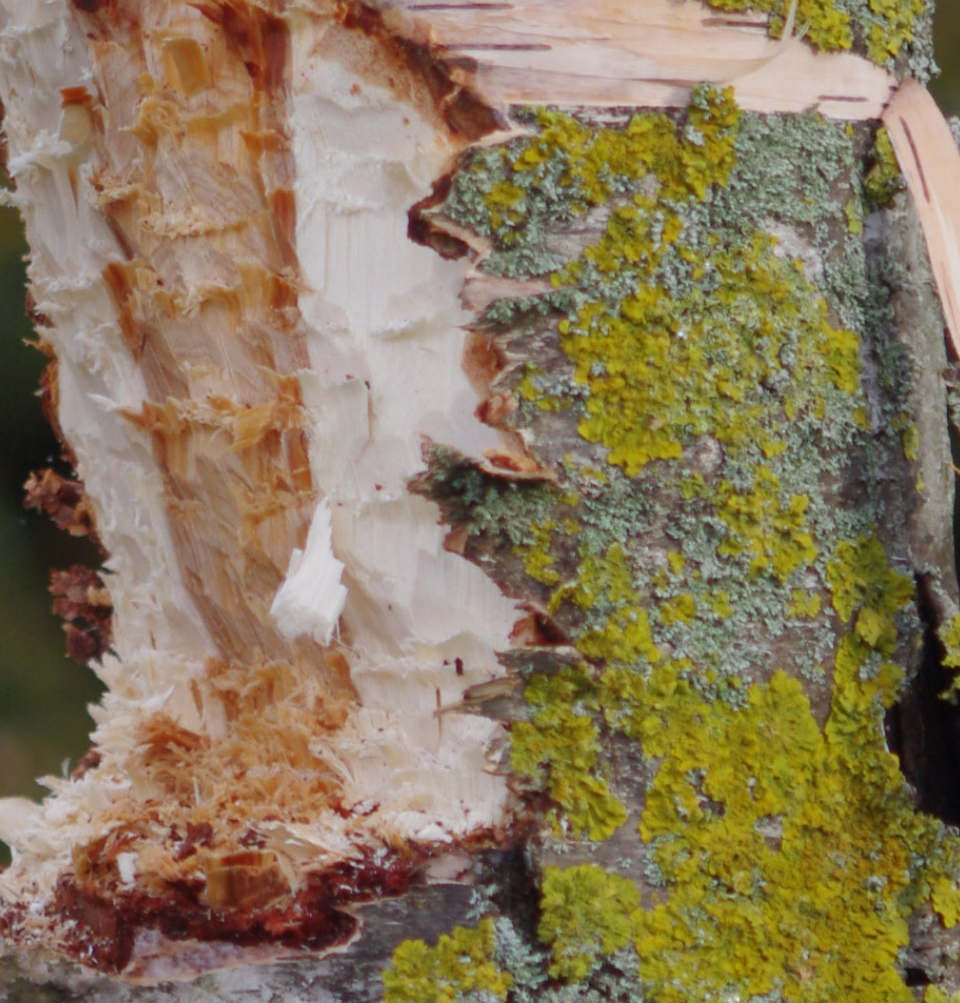

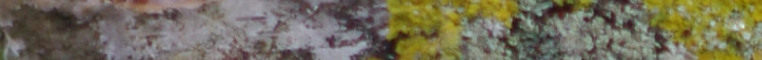

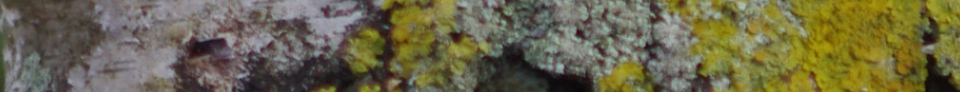

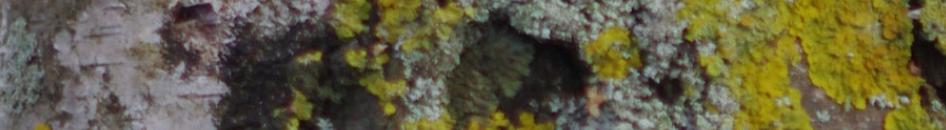

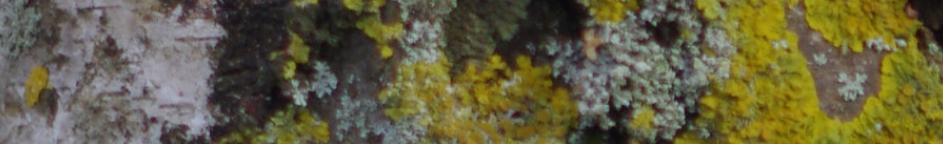

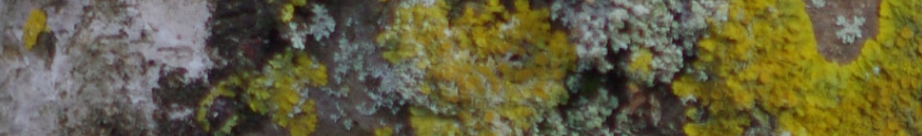

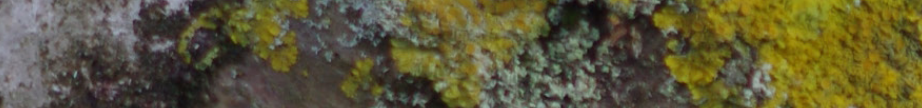

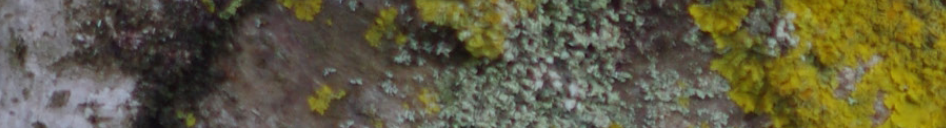

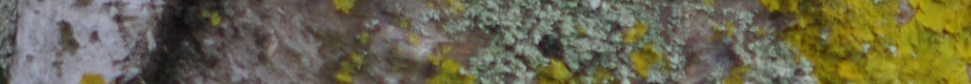

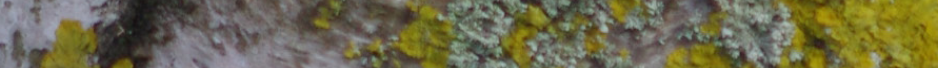

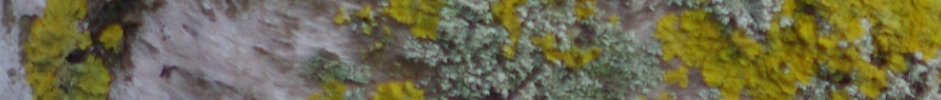

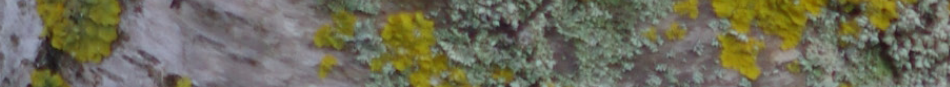

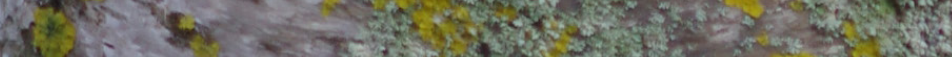

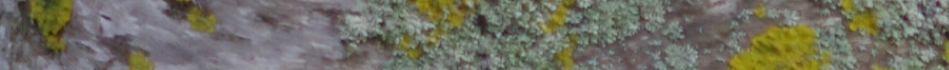



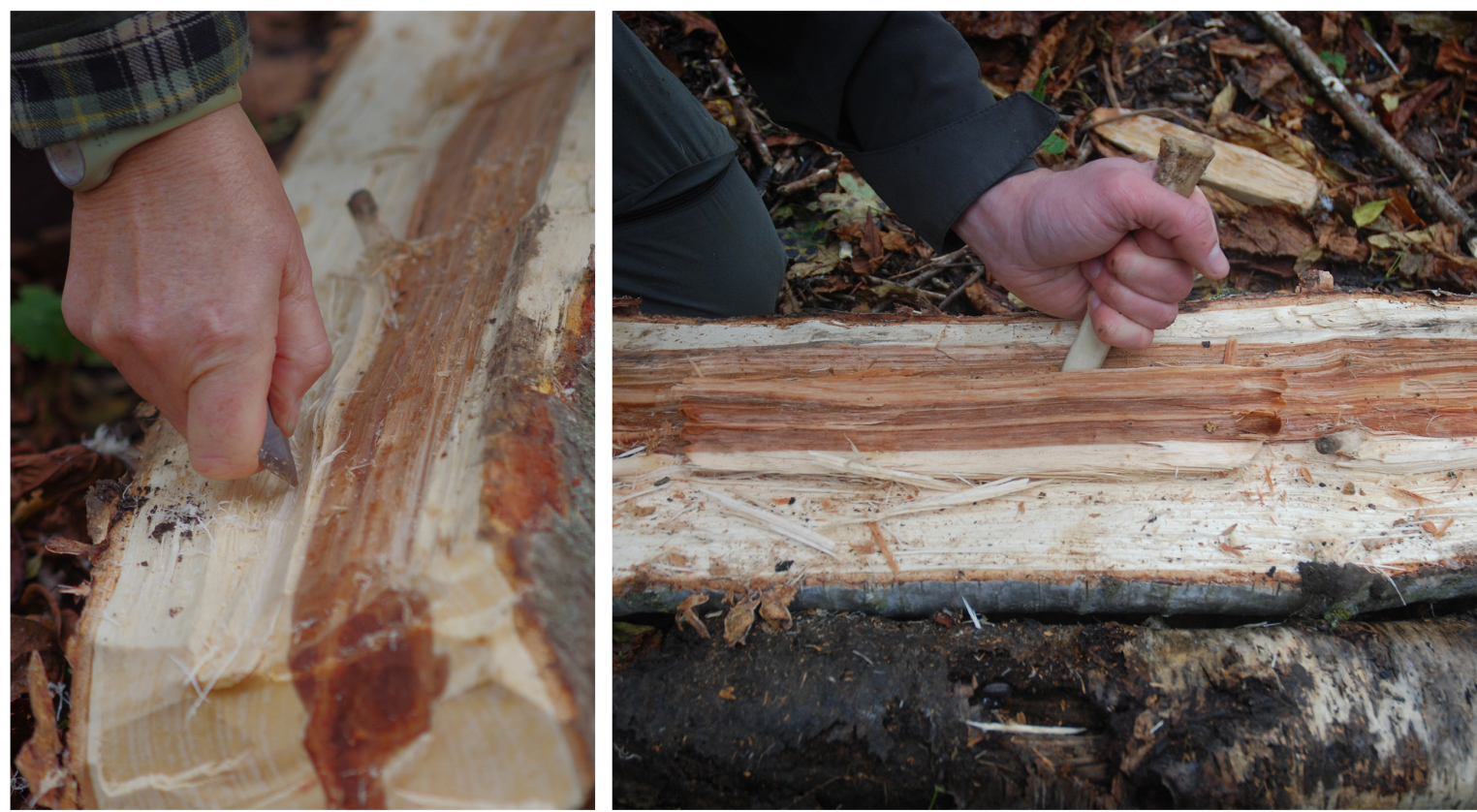

Figure 28.13: (left) Flint flake being utilised to produce longitudinal grooves as part of groove-and-split woodworking; (right) bone chisel used as splitting wedge as part of groove-and-split technique (Copyright left photograph Don Henson, CC BY-NC 4.0. Copyright right photograph Michael Bamforth, CC BY-NC 4.0).

which identified two awls with traces of plant polish that may possibly indicate woodworking. Flint flakes were successfully used as part of groove-and-split woodworking during experimental work (Figure 28.13).

Elk antler mattocks were formed from either the beam, pedicle and adhering frontal bones or the beam and palmate portion. These tools would have been hafted with either a roundwood stem or heartwood dowel (Chapter 29). Clark recovered six antler mattocks and the recent excavations uncovered a further finished example $<113836>$ and an item interpreted as a possible roughout (Chapter 24). Experimental work showed this type of tool to be effective as a woodworking tool; unfortunately the condition of the artefact did not allow for microwear analysis (Chapters 24 and 29).

A single large bone chisel fashioned from a split aurochs metatarsal was recovered $\langle 117517\rangle$ (Chapter 24). Although analysed for use wear traces, any evidence of function had been obliterated by a sharpening event. The chisel does not seem to have been hafted and is of a sufficient size to be held in the hand. There was clear bruising and percussion damage to the butt end of the tool to suggest that it was repeatedly hit with a heavy object; however, there was no breakage associated with this to suggest long-term or heavy usage. This item is of a suitable size and form to be used as a woodworking tool or a splitting wedge. Experimental work proved slightly smaller bone chisels to be very efficient and useful woodworking tools as well as splitting wedges (Figure 28.13).

It has been suggested that the numerous worked antler tines $(n=175)$, originally identified by Clark, may have been utilised as wedges for splitting wood (Mellars and Dark 1998) and experimental work carried out in October 2014 proved them to be very effective for this undertaking. However, it is cautioned that these items are extremely numerous and would have been suitable for a number of different tasks (Chapter 24). Two pieces of split willow, $<116520>$ and $<103149>$, may have been wooden splitting wedges (Chapter 29). In addition, there are several longitudinally split pieces of animal long bone that have been interpreted as the discards from which blanks have been split from to fabricate barbed points (Chapter 24); however, these could conceivably have been used as splitting wedges, though preservation of these items was too poor to allow microwear analysis. 
Finally, stone $<96759>$ has a series of parallel grooves that contain traces of microwear revealing wood and or antler polish, raising the possibility that the item was used perhaps to sharpen barbed points or as an arrow straightener (Chapter 34).

\section{Felling and trimming}

There are several different felling techniques that the woodworkers of Star Carr may have used. It is possible that the tree may have been ringed 'beaver style'. Alternatively, a 'cut to fall' technique familiar to modern woodsman with a front cut and back cut may have been used. Either of these techniques can be achieved through axing/adzing or by using a notch-and-split technique (Figure 28.14). Three pieces of possible notch-and-split debris that may be indirect evidence of felling have been described above.

There are 94 items identified as entire trunks of large trees. Seven of these were growing on the lake edge and are lying in situ where they have fallen into the waterlogged deposits and $\langle 109924\rangle$, which formed part of the western lake edge platform, has a root bole present at the proximal end showing the use of a naturally fallen tree. However, only two trees display working at the proximal/butt end possibly related to felling. Both are from the detrital wood scatter: tree $<109557>$ has been tangentially split at one end and possibly trimmed at the other. It is unclear which end is proximal and which distal; tree $<110365>$ has been reduced to a half split

\section{Axe/Adze style felling}
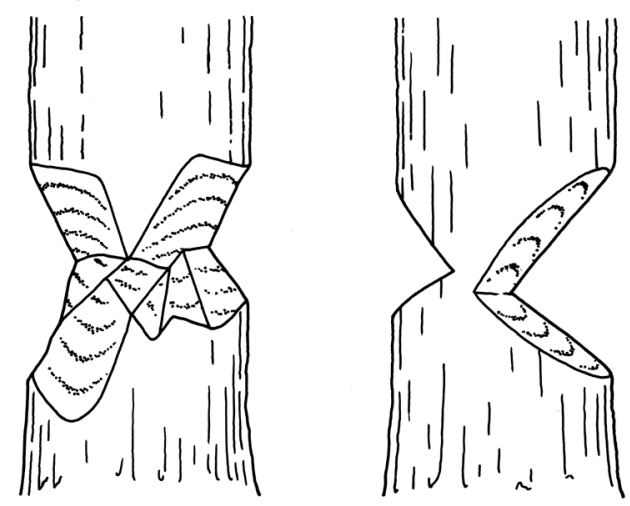

Ringed 'beaver style'

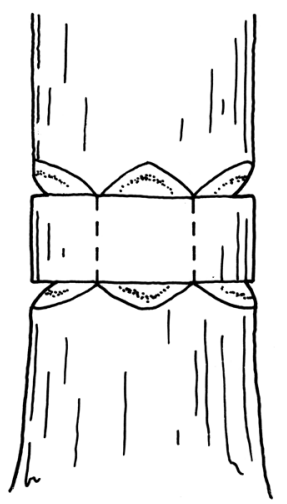

Cut to fall

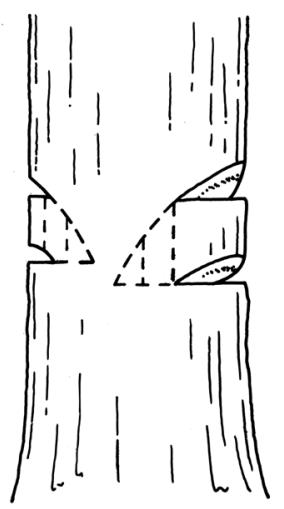

Notch and split style felling

Figure 28.14: Possible felling techniques (Copyright Chloe Watson, CC BY-NC 4.0). 
at the proximal end-the split face appeared torn and parallel lines of chop marks were present, cutting across the grain. These may represent faint traces of notch-and-split felling. It is also possible that fire may have been used to assist in the felling of trees. Two trees show evidence of charring: <99893> is lightly charred on one face at the proximal end. However, this charring does not seem extensive or intense enough to be associated with felling. The proximal end of fallen tree $<109922>$ has been completely charred through and it seems likely that this tree was felled by fire. However, there is no way to know if this was a deliberate cultural action designed to fell the tree or merely a by-product of a fire on the lake edge.

Generally limited to stone tool woodworking assemblages, the chop and tear technique of trimming small diameter roundwood stems (c. 20-50 mm) involves bending the stem and chopping it, allowing it to tear, and then chopping again to sever the stem, leaving a distinctive stepped edge. It is known from other UK stone tool woodworking assemblages such as Etton Neolithic causewayed enclosure (Taylor 1998, Figures 169 and 170) and has been proved effective through experiment (Jørgensen 1985, 35-37 and figure 41). Similar evidence was also recorded from the Danish Ertebølle site of Tybrind Vig (Johansen 2013, figure 7). Twenty-four examples of chop and tear have been recorded from the Star Carr assemblage. This includes a particularly interesting example $<103190>$ that shows evidence of both chop and tear and beaver gnawing (Figure 28.15).

The presence of cross-grain woodchips is of particular interest. When comparing the bronze tool-derived Bronze Age woodchip assemblage recorded at Flag Fen to the stone tool-derived Neolithic woodchip assemblage recorded at Etton, Taylor $(2001,182-3)$ points to the lack of cross-grained woodchips in the latter assemblage and suggests that it may be particularly hard to detach a cross-grained wood chip with a stone axe without suffering some damage to the tool. As such it is interesting to note their presence in this, the earliest woodworking assemblage currently known from Europe. Further experimental work may help to elucidate the efficacy of stone axes when used to work across the grain.
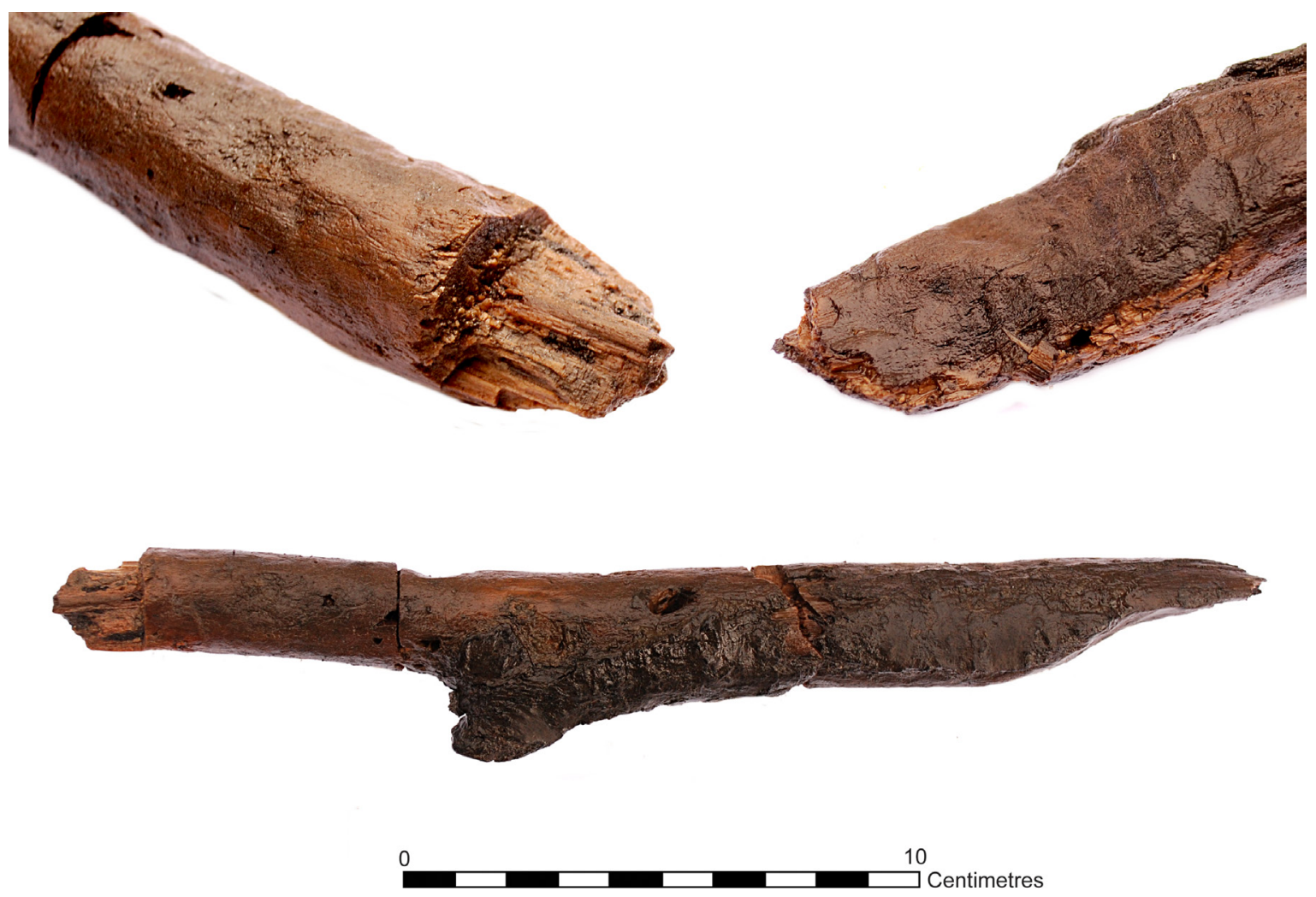

Figure 28.15: <103190> showing chop and tear at distal end and beaver gnawing at the proximal end and side branch (Copyright Michael Bamforth, CC BY-NC 4.0). 


\begin{tabular}{|l|r|r|}
\hline Conversion & Frequency & \multicolumn{1}{l|}{$\%$} \\
\hline Radial & 151 & 11.6 \\
\hline Radial 1/2 & 79 & 6.1 \\
\hline Radial 1/3 & 20 & 1.5 \\
\hline Radial 1/4 & 20 & 1.5 \\
\hline Radial 1/6 & 1 & 0.1 \\
\hline Radial 1/8 & 5 & 0.4 \\
\hline Tangential & 729 & 56.2 \\
\hline Tangential, outer surface split away & 6 & 0.5 \\
\hline Tangential outer & 194 & 14.9 \\
\hline Tangential and radial & 15 & 1.2 \\
\hline Cross grain & 8 & 0.6 \\
\hline Unknown & 70 & 5.4 \\
\hline Total & 1298 & 100.0 \\
\hline
\end{tabular}

Table 28.5: Conversions recorded from the Star Carr wood assemblage (excluding woodchips).

\begin{tabular}{|l|r|r|}
\hline Conversion & Frequency & \multicolumn{1}{l|}{} \\
\hline Off roundwood & 9 & 4.9 \\
\hline Radial & 40 & 22.0 \\
\hline Tangential & 113 & 62.1 \\
\hline Cross grain & 2 & 1.1 \\
\hline Unknown & 18 & 9.9 \\
\hline Total & 182 & 100.0 \\
\hline
\end{tabular}

Table 28.6: Conversions of the Star Carr woodchip assemblage.

\section{Splitting}

\section{Overview}

The assemblage at Star Carr has a large quantity of split material in a variety of conversions. Tangential material dominates $(73 \%)$, with moderate quantities of radially cleft material $(21.3 \%)$ and occasional cross grained items (1\%) also present (Table 28.5). Interestingly, this closely matches the alignments of the recorded woodchip assemblage (Table 28.6). During the recording of the wood assemblage, it was noted that many of the split surfaces appeared rougher than would be expected, or perhaps torn. The cause of this is unknown.

\section{Tangential outer splits}

A striking feature of the worked wood assemblage recorded from Star Carr is the strong bias towards tangential outer splits, with bark edge still present (Figure 28.16). The split tends to fade out at either end of these timbers, which can range in length from 1.0-3.6 $\mathrm{m}$. The presence of so many tangential outer split timbers within this assemblage is extremely unusual. In a later assemblage such material would often be generated as waste material from squaring up timbers into boxed heart or half splits. However, there is no evidence from the 

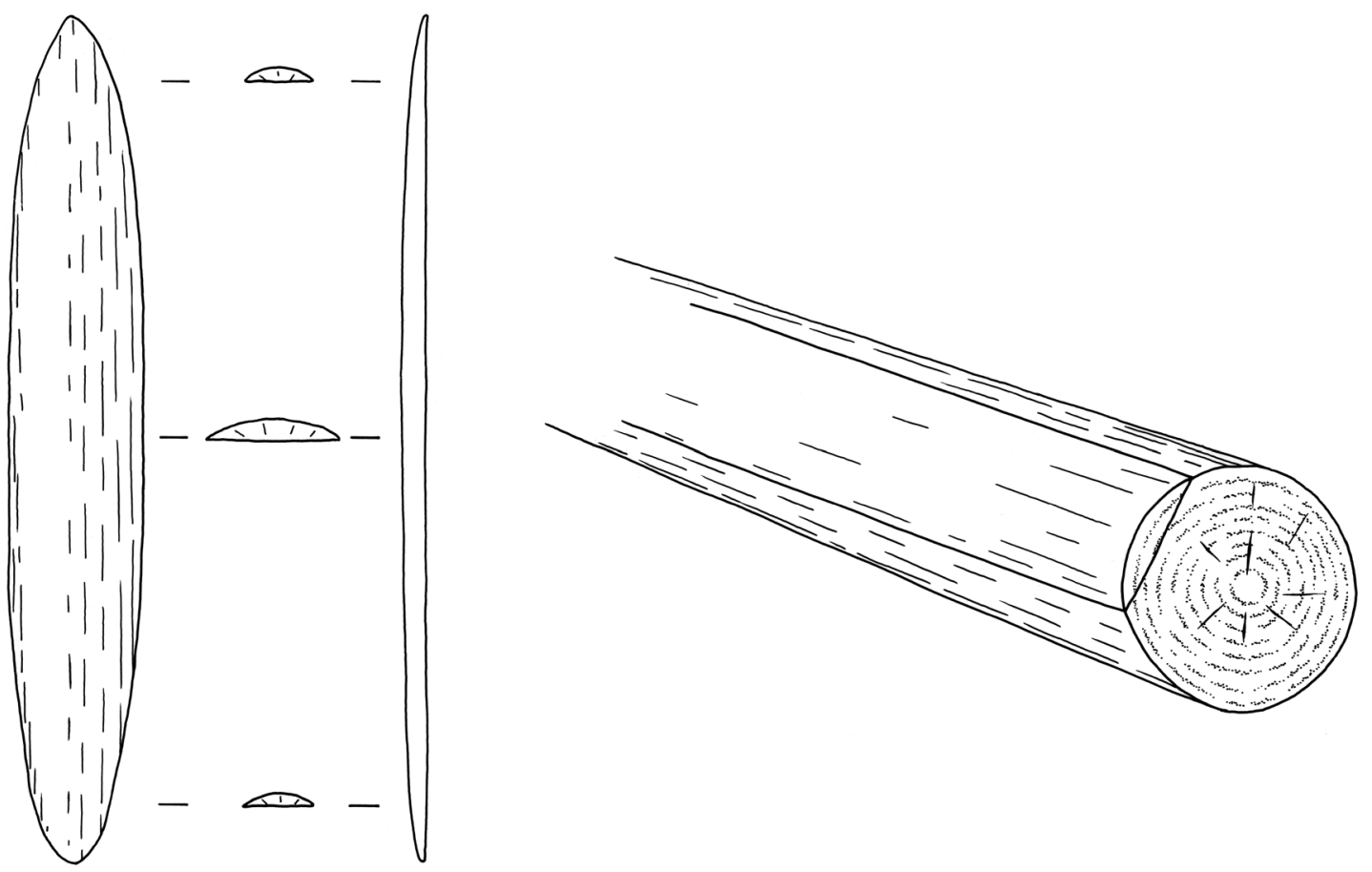

Figure 28.16: Tangential outer splits, often fading / feathering out at both ends (Copyright Chloe Watson, CC BY-NC 4.0).

wood assemblage at Star Carr of such boxed-up material to suggest that this is the case here. There are several items which have had a single outer surface tangentially cleft away, which would produce an offcut that was a tangential outer cleft. However, there are only six of these items (Table 28.5) which cannot account for the large number of tangential outer splits. Instead, the tangential outer splits seem to be, for the most part, finished products rather than waste material. This leads to the possibility that some of these timbers were being harvested from living, standing trees. This practice is known ethnographically. Indigenous peoples of the Pacific North-West Coast split huge structural timbers from living cedar trees (Stewart 1984, 42), and the Bindibu people of Central Western Australia cut parallel sided planks from standing Mulga trees from which to produce spear throwers (Thompson 1964) using a technique similar to the groove-and-split technique discussed below.

Experimental work carried out during October 2014 showed it to be surprisingly easy to cleave planks from a standing tree. A notch was cut out at the top of the desired split to allow the insertion of splitting wedges. Wood, bone and antler wedges were used to chase the split down the trunk (Figure 28.17). This resulted in a stepped, almost cross cut distal/top end to the timber and a feathered out lower/proximal end. The tree used had a diameter of $165 \mathrm{~mm}$. It took 20 minutes to make the top cut and a further 30 minutes to split away a 1.6 $\mathrm{m}$ long timber. DP and MB felt that this could be achieved in perhaps half the time with practice. It was noted that to split a longer timber from a standing tree, one would need to be at height having either climbed the tree or used a ladder or similar. However, it was not possible to replicate the feature noted on several split archaeological timbers where the split fades or feathers out at both ends. It is still unclear which technique produced this result.

\section{Groove-and-split}

Previous investigations at Star Carr identified the presence of longitudinal parallel grooves on the faces of timbers and a tendency for both parallel sided timbers and long, thin, parallel sided woodworking debris (Mellars et al. 1998). 

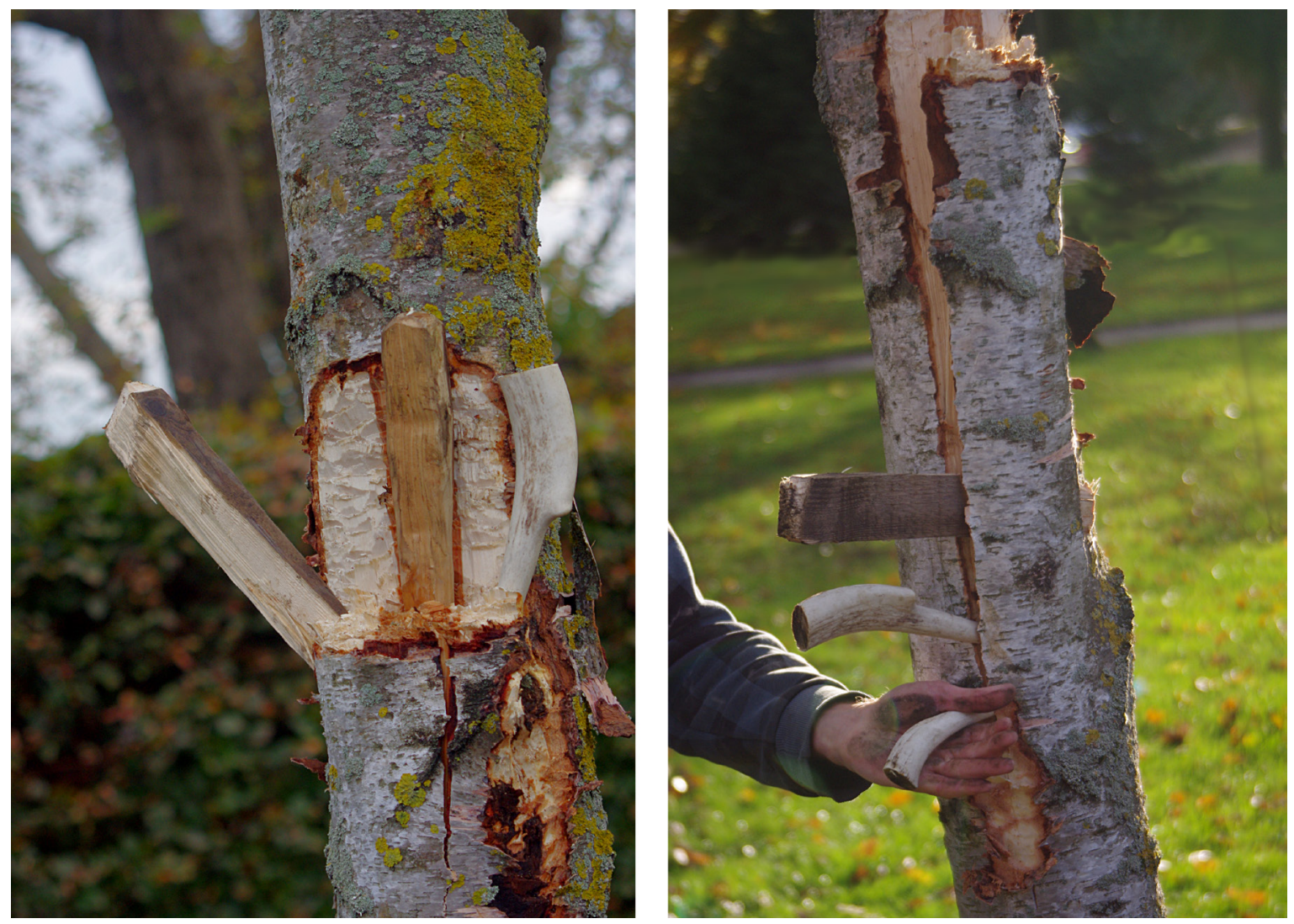

Figure 28.17: Tangential outer timber being split from a standing tree using wood and antler wedges (Copyright Don Henson, CC BY-NC 4.0).

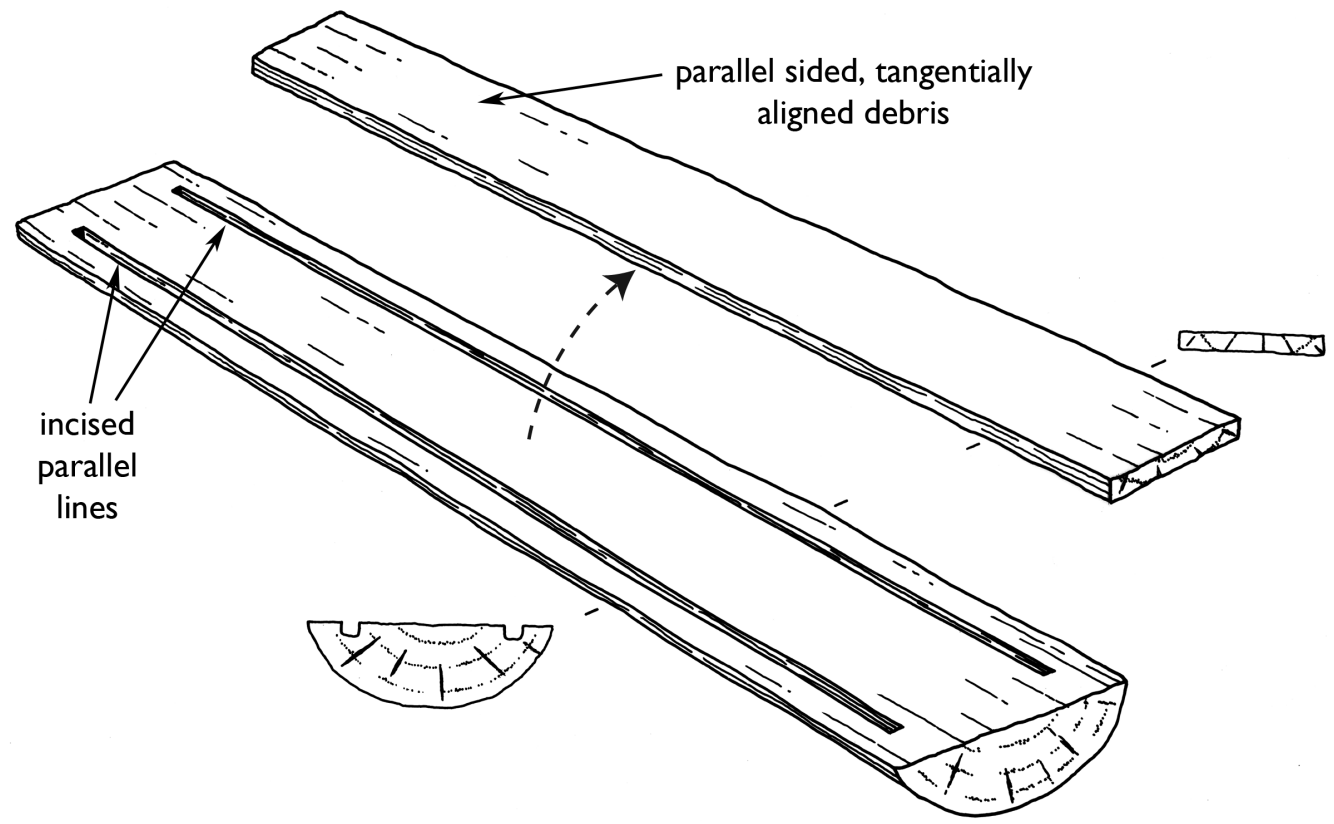

Figure 28.18: Schematic representation of groove-and-split (Copyright Chloe Watson, CC BY-NC 4.0). 

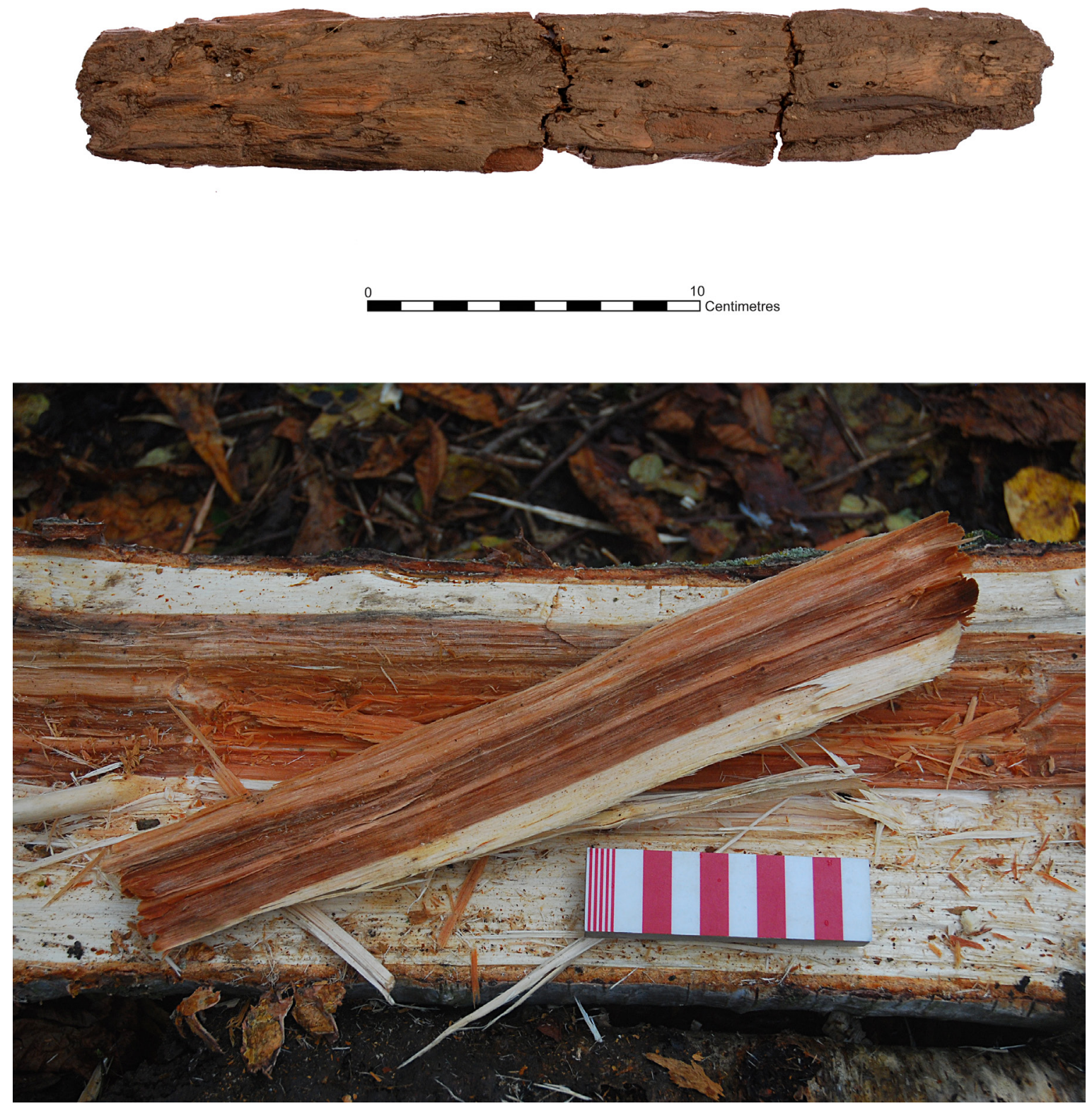

Figure 28.19: Groove-and-split debris $<103676>$ (top) and debris produced during experimental work (bottom) (Copyright Michael Bamforth, CC BY-NC 4.0).

Similar traces have been recorded at Etton Neolithic causewayed enclosure (Taylor 1998a), the Raunds Neolithic Long barrow (Taylor and Bradley 2007) and the Late Mesolithic Carlisle Northern Development Route (Taylor and Bamforth 2013). These traces, distinct to stone-tool woodworking assemblages, may have been produced by a previously unrecognised woodworking technique: groove-and-split. It seems that parallel grooves have been used to control the edges of splits and that the debris has been split or gouged from between the parallel grooves (Figures 28.18 and 28.19). This hypothesised technique is somewhat similar to the groove-and-splinter technique applied to antler (Chapter 24) or to the notch-and-split technique used for tree felling and boat building discussed above.

This technique was tested on a small scale during experimental work. Parallel grooves were incised into the surfaces of split birch timbers with both flint flakes and bone chisels. The section of wood between the grooves 

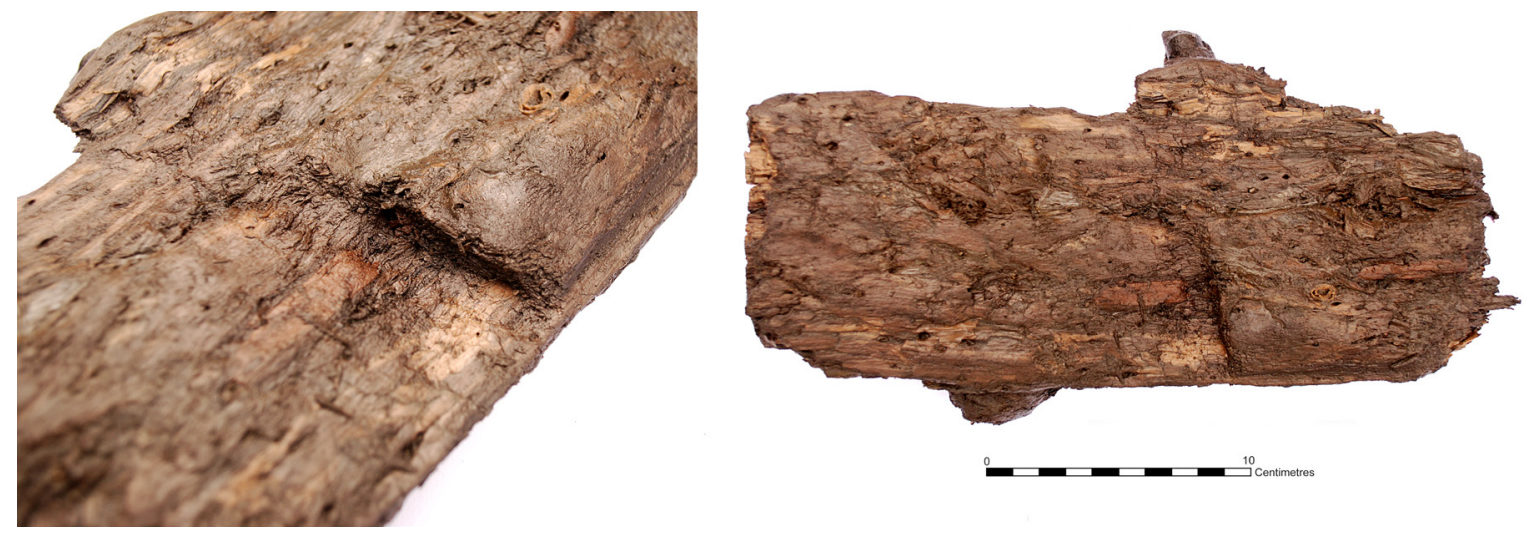

Figure 28.20: Diagonal groove feature on <99211> (Copyright Michael Bamforth, CC BY-NC 4.0).

was then split away using antler tines and a bone chisel. Although the experimental work did produce the woodworking traces recorded from Star Carr in the form of parallel grooves and long, parallel sided pieces of woodworking debris, it was noted as being quite a slow technique and it was unclear why it would have been necessary to split thin pieces away from the surfaces of timbers.

There are 12 items from the recent excavations, generally of medium to large size, that show removal scars from hewing or splitting several large pieces away in the tangential plane.

\section{Diagonal groove/gouge mark}

A small group of split timbers recorded during the recent investigations at Star Carr also have an unusual diagonal groove or gouge mark present on the split surface (Figure 28.20). Previous experimental work carried out at Flag Fen had shown that using seasoned oak wedges to split wood does not leave any traces on the split timber. Furthermore, traces of splitting wedges on the split surfaces of timbers are not seen from prehistoric woodworking assemblages. Therefore, it was hypothesized that the diagonal features may have been produced by the use of antler tines as splitting wedges. However, experimental work using antler tines to split birch timbers showed this not to be the case and the cause of these groove features is still not understood.

\section{Wider context}

Star Carr currently sits alone in the UK as the only large assemblage of Early Mesolithic worked wood. However, there are comparable assemblages in Europe. Investigations at the submerged Danish site of Tybrind Vig have provided evidence for Mesolithic carpentry and woodworking practices relating to the Ertbølle period (Anderson 2013), including radial and tangential splitting, trimming of roundwood stems and the remains of felling scars, carried out with both core (generally larger items) and flake (generally smaller roundwood poles) flint axes. Dowel technology and species selection is also well represented in a series of hafts, digging sticks and bows. These tended to be extremely well finished, obliterating any evidence of initial production. A small number of woodchips $(n=13)$ were also present that provide evidence for possible 'char and scrape' woodworking at the site. Like at Star Carr, the propensity for straight hazel rods has also led to the suggestion of coppicing at Tybrind Vig, in this case to produce stems for the construction of fish weirs.

In the UK, investigations at the submerged landscape of Bouldnor Cliff (Isle of Wight), have also provided evidence for Late Mesolithic woodworking in terms of tangentially split timber and a possible log boat fragment (Rich et al. 2016). The assemblage recovered from Bouldnor Cliff is relatively small (although large in terms of Mesolithic worked wood in the UK) and, coupled with taphonomic issues resulting from the burial environment, this has led to some difficulties differentiating anthropogenic from natural material. To this end, a 
programme of experimental work has been undertaken to better understand Mesolithic woodworking practices, focusing particularly on the use of non-stone tools, including bone chisels and wooden wedges (Rich et al. 2016).

\section{Conclusions}

Although there is evidence for beaver activity, both predating the human activity at Star Carr and continuing throughout the phases of deposition, the volumes of beaver-modified wood $(n=24)$ are small in comparison to the quantity of split, trimmed and hewn pieces made by Mesolithic woodworkers ( $\mathrm{n}=1602)$.

The appearance of many of the roundwood stems suggests that they may be derived from coppice. This is represented by a spike in growth rings of 2-3 years seen amongst the roundwood with morphological evidence of coppicing, and also a slightly elevated diameter-to-age ratio for the roundwood possibly derived from coppicing compared to the control group. This may be an indicator of woodland management in the form of intentional coppicing: however, this may simply be a result of natural re-growth of material from trees felled either by humans or beavers.

However, there is much evidence that the woodworkers at Star Carr showed a high level of competence and although complex carpentry in the form of joints or fixings does not seem to have been used, the woodworkers had an excellent understanding of both splitting and dowel technology. There is also evidence for the use of multiple twisted stems of willow plied together to produce an early form of rope. Entire trees were felled and then utilised whole or split down into large timbers, several of which were impressively long in a prehistoric context. It also seems likely that as well as harvesting regrowth 'coppice' stems, the woodworkers at Star Carr were also harvesting planks from living trees, demonstrating a husbandry of available woodland resources.

From traces on the wood, items in the finds assemblage and the use of microwear analysis and experimental archaeology, it has been possible to identify a suite of tools that formed part of the Mesolithic woodworking toolkit, which appears to have consisted of flint axes/adzes, blades, burins, denticulates/notched pieces, scrapers, flakes, fragments, chunks, nodules and coarse stone burnishing tools. In addition, results from our experimental research suggests the use of splitting wedges made of wood, bone and antler, and the probable use of antler mattocks and bone chisels, which proved to be highly functional tools for working wood.

As is often the case when carrying out experiments which rely on skill, knowledge and crafts that are no longer commonplace, a real difference was observed in the speed and quality of work that could be achieved by skilled versus unskilled labour. It was also interesting to note that during the initial manufacture phase, which in these experiments was generally carried out with a flint tranchet axe, the more experienced woodworker produced relatively larger woodchips and debris than the less experienced woodworker; the former worked more efficiently to detach larger pieces of debitage for each strike of the tool.

Although the wood assemblage and experimental work have provided a wealth of evidence for woodworking and basic carpentry practices at Star Carr, many questions still remain. For instance, the efficacy of groove-and-split, the performance of flint axes when working across the grain and the creation of split timbers that fade out at both ends are still poorly understood. It is through further experimental work, alongside the analysis of excavated remains, that we will further our understanding of Mesolithic woodworking practices.

Overall, it should not be surprising that Mesolithic woodworkers had a firm understanding of the use and selection of available resources and had perfected many basic carpentry techniques, particularly when considered in conjunction with the fine and precise microlith technology in use at the time, and in light of the extreme antiquity of the utilisation of wood for artefacts (Chapter 29). When excavating and analysing worked Mesolithic wood, it seems prudent to start from a perspective that expects relatively advanced woodworking technology, carried out with great sympathy to the naturally available resources, in order to fully understand what would have been a critical and versatile technology of the period. 